\title{
A Comprehensive Review on Oxygen Reduction Reaction in Microbial Fuel Cells
}

\section{Pooja Dange ${ }^{1, \#}$, Nishit Savla ${ }^{1, \#}$, Soumya Pandit ${ }^{2, *}$, Rambabu Bobba $^{3}$, Sokhee P. Jung ${ }^{4}$, Piyush Kumar Gupta ${ }^{2}$, Mohit Sahni ${ }^{5}$ and Ram Prasad ${ }^{6,}$}

\author{
${ }^{1}$ Amity Institute of Biotechnology, Amity University, Mumbai, 410206, India \\ ${ }^{2}$ Department of Life Sciences, School of Basic Sciences and Research, Sharda University, Greater Noida, 201306, India \\ ${ }^{3}$ Department of Physics, Southern University and A\&M College, Baton Rouge, 70813, USA \\ ${ }^{4}$ Department of Environment and Energy Engineering, Chonnam National University, Gwangju, 61186, Korea \\ ${ }^{5}$ Department of Physics, School of Basic Sciences and Research, Sharda University, Greater Noida, 201306, India \\ ${ }^{6}$ Department of Botany, Mahatma Gandhi Central University, Bihar, 845401, India \\ *Corresponding Authors: Soumya Pandit. Email: sounip@gmail.com; Ram Prasad. Email: rpjnu2001@gmail.com \\ ${ }^{\#}$ Both the authors have equal contributions
}

Received: 15 January 2021 Accepted: 28 July 2021

\begin{abstract}
The focus of microbial fuel cell research in recent years has been on the development of materials, microbes, and transfer of charges in the system, resulting in a substantial improvement in current density and improved power generation. The cathode is generally recognized as the limiting factor due to its high-distance proton transfer, slow oxygen reduction reaction (ORR), and expensive materials. The heterogeneous reaction determines power generation in MFC. This comprehensive review describes-recent advancements in the development of cathode materials and catalysts associated with ORR. The recent studies indicated the utilization of different metal oxides, the ferrite-based catalyst to overcome this bottleneck. These studies conclude that some cathode materials, in particular, graphene-based conductive polymer composites with non-precious metal catalysts provide substantial benefits for sustainable development in the field of MFCs. Furthermore, it also highlights the potentiality to replace the conventional platinum air cathode for the large-scale production of the next generation of MFCs. It was evident from the experiments that cathode catalyst needs to be blended with conductive carbon materials to make cathode conductive and efficient for ORR. This review discusses various antifouling strategies for cathode biofouling and its effect on the MFC performance. Moreover, it also depicts cost estimations of various catalysts essential for further scale-up of MFC technology.
\end{abstract}

\section{KEYWORDS}

Cathode; catalyst; microbial fuel cell (MFC); nanomaterials; oxygen reduction reaction (ORR); biofouling; biocathode 


\section{Introduction}

Ever since the industrial revolution, the food, water, and energy resources have been getting polluted and depleted with rising population and urbanization [1]. Due to the never-ending and increasing energy demands of the world coupled with resource crisis, research for finding a sustainable source of energy is being carried out worldwide. Fossil fuels have been the sole source to produce energy all across the globe for 100 years, the combustion of these fuels results in excessive $\mathrm{CO}_{2}$ emissions resulting in global climate change [2]. On a global scale carbon-neutral, sustainable energy sources have to be developed to replace these fossil fuels. A steady increase in the concentration of atmospheric $\mathrm{CO}_{2}$ was observed from $315 \mathrm{ppm}$ in 1957 to $413.22 \mathrm{ppm}$ in 2020. Industrial emissions and fossil fuel usage have led to an increase of about $40 \%$ in the total atmospheric $\mathrm{CO}_{2}$ and about a $78 \%$ rise in the greenhouse gases concentration from 1970 to 2010. Hence, the accumulation of carbon dioxide led to the absorption and re-emission of heat which in turn attributes to an additional warming of the planet. Alternative energy resources for fuel supply are being used in an increasing trend [3]. This includes a solution that produces energy from organic waste and processes it concurrently by microbial fuel cells (MFCs) [4-7].

MFCs are bioelectrochemical systems that are capable of transforming chemical energy into electricity $[8,9]$. A standard MFC is composed of an anode, and a cathode, may or may not be separated by an ionexchange membrane [10-15]. The anode is a site where, through metabolic pathways, electroactive bacteria produce electrons and protons under anaerobic conditions [10-15]. Electrons produced by electroactive bacteria are transported from the anode, via an external circuit to the cathode to reduce. In the presence of oxygen, the oxygen serves as a terminal electron acceptor and eventually reduces on the cathode and becomes a water molecule [10-15]. The working principle and the schematic of a typical MFC are shown in Figs. 1A-1B.

In the performance of the cell, electrodes play a critical role; hence, the choice of electrode material is a crucial component of the system's construction [16,17]. Without compromising the properties of the ideal electrode material, researchers are actively designing high-performance, low-cost electrode materials. An electrode material with strong electrical conductivity [18,19], biocompatibility [20,21], high bacterial adhesion [22,23], surface area, corrosion-resistant [24,25], and capable of manufacturing in any desired form is considered to be the perfect anode material for MFC construction, while an efficient cathode should have high conductivity and surface area to volume (SA/V) ratio, it should be non-corrosive and most fouling resistant. In the cathode, oxygen, as gas reacts and is combined with protons $\left(\mathrm{H}^{+}\right)$present in the electrolyte and electrons $\left(\mathrm{e}^{-}\right)$, are transported via metallic wire from the anode. This ORR reaction on the cathode surface needs high energy. Indigenous cathodes consume energy, consequently, power generation reduces. Therefore, the cathode catalyst plays a key role in the efficiency of the MFCs alongside the anode and cathode holding a large share in the construction cost of the MFCs [26-29]. For a successful ORR, the activity of cathode catalysts is highly vital [30,31]. The best cathode catalyst in an MFC provides efficient ORR kinetics, durability, lower over-potential activation, and is cost-effective [32,33]. Therefore, to reduce the cathodic overpotential [34], a highly effective catalyst is required. During the early phase of testing, a premium noble metal dust platinum was used; however, various types of non-metal materials were used as an illustration catalyst based on metal and carbon. Carboncombination of carbon-metal along with medium metal-nitrogen-carbon catalysts were found very effective for efficient ORR [35]. Power output was evaluated between MFCs with various ORR catalysts. The present review overall discusses the usage of various types of cathode catalysts in the MFCs.

\subsection{Cathodic Factors Affecting MFC Performance}

Several methods of reduction are known as cathode reactions in MFCs. Fundamentally, a cathode is a site where the final electron acceptor reduces on the cathode surface by collecting the anode-generated electron and the proton is percolated from the anode through the separator. To prevent electrical short 
circuits, separators separate both electrodes. However, for retaining electroneutrality, same number of protons are moved to the cathode by a separator such as an ion-exchange separator. Oxygen as an electron acceptor under aerobic cathodes is largely attributed to its intense normal capacity with infinite supply, which also reduces on the cathode surface (Fig. 2). Oxygen reduction involves two alternative mechanisms depend on the oxygen at the interface of a cathode and the catholyte $\mathrm{pH}$. The appropriate reaction is for the water to be produced by the four-electron pathway, whereas in an incomplete oxygen reduction the two-electron mechanism leads to the creation of hydrogen peroxide.

$\mathrm{O}_{2}+4 \mathrm{e}^{-}+4 \mathrm{H}^{+} \rightarrow 2 \mathrm{H}_{2} \mathrm{O}, \quad \mathrm{E}^{\mathrm{o}}=1.23 \mathrm{~V}$ (vs. SHE)

$2 \mathrm{O}_{2}+4 \mathrm{e}^{-}+4 \mathrm{H}^{+} \rightarrow 2 \mathrm{H}_{2} \mathrm{O}_{2}, \quad \mathrm{E}^{\mathrm{o}}=0.295 \mathrm{~V}$ (vs. SHE)

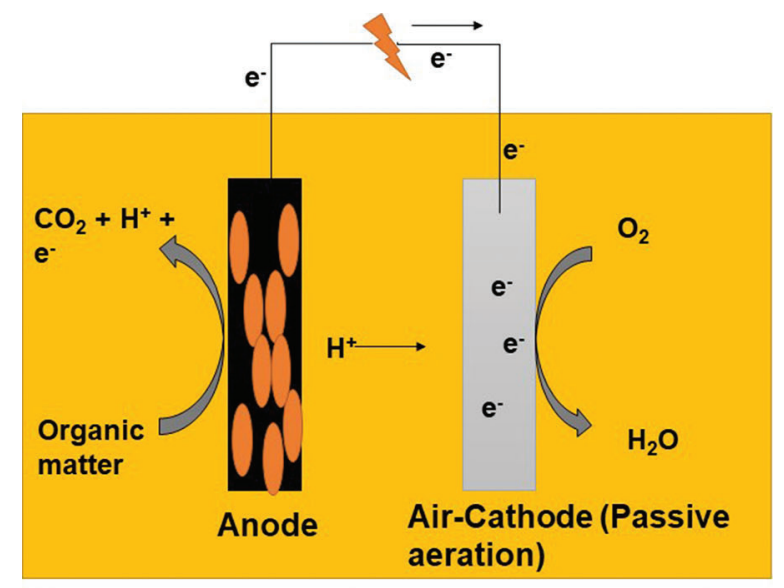

(A)

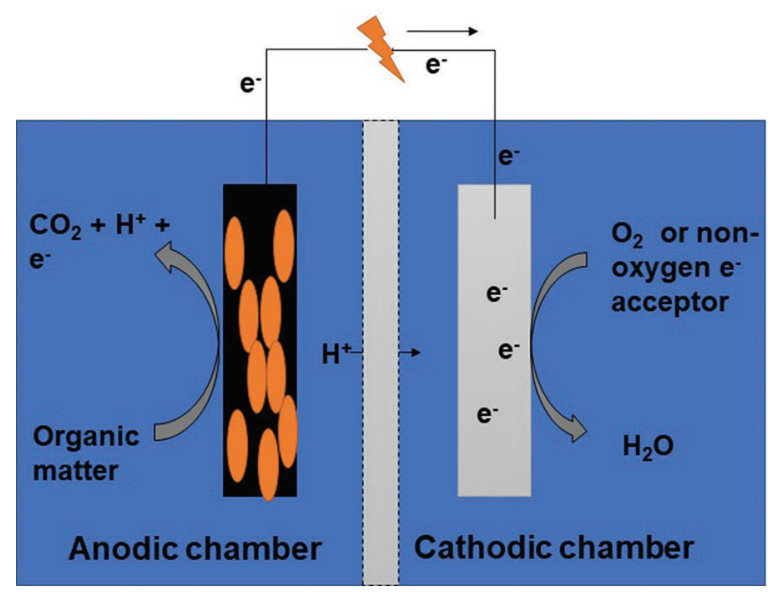

(B)

Figure 1: (A) Schematic representation of a single chambered microbial fuel cell (MFC); (B) Schematic representation of a dual chambered MFC

The current generation in the MFC system is highly dependent on the cathode's reduction kinetics and an important part of the voltage generated is used to balance the absence of current. The reaction kinetics is limited by an activation energy barrier that prevents the oxidant from being transformed into a reduced form. 
In an MFC, a portion of the cathode potential is then lost until the current is generated to overcome this activation barrier. The lack of potential due to activation is referred to as the loss of cathodic activation $\left(\eta_{\text {cat }}\right)$. Such cathodic limits, including ohmic losses and losses in mass transport. The operation of an MFC is also regulated by ohmic overpotential, which means the voltage that is lost to the transport of electrons and protons, and this loss often follows the law of ohm:

$\eta_{\text {Ohmic }}=\mathrm{iR}$ Ohmic

The cathodic ohmic resistance is a combination of ionic $\left(\mathrm{R}_{\text {ion }}\right)$ and electrical $\left(\mathrm{R}_{\text {elec }}\right)$ resistances, and also includes an electrode, electrolyte, and interconnection resistance:

$\mathrm{R}_{\text {Ohmic }}=\mathrm{R}_{\text {ion }}+\mathrm{R}_{\text {elec }}$

Mass transport is distinguished by the method of supplying oxidants and removing products at an MFC's cathode. Reactant degradation happens due to inefficient mass transfer which impacts both the voltage of the Nernstian cell and the reaction speeds, resulting in a lack of function. At high current density and increasing in magnitude, mass transfer losses occur with increasing current density. As compared to the anode, due to oxidant transport, the impact of mass transport loss is much greater in the cathode compartment. There are very important factors affecting cathode performance such as cathode materials, cathode surface area, cathode catalyst, cathodic electron acceptor, and cathodic operating conditions.
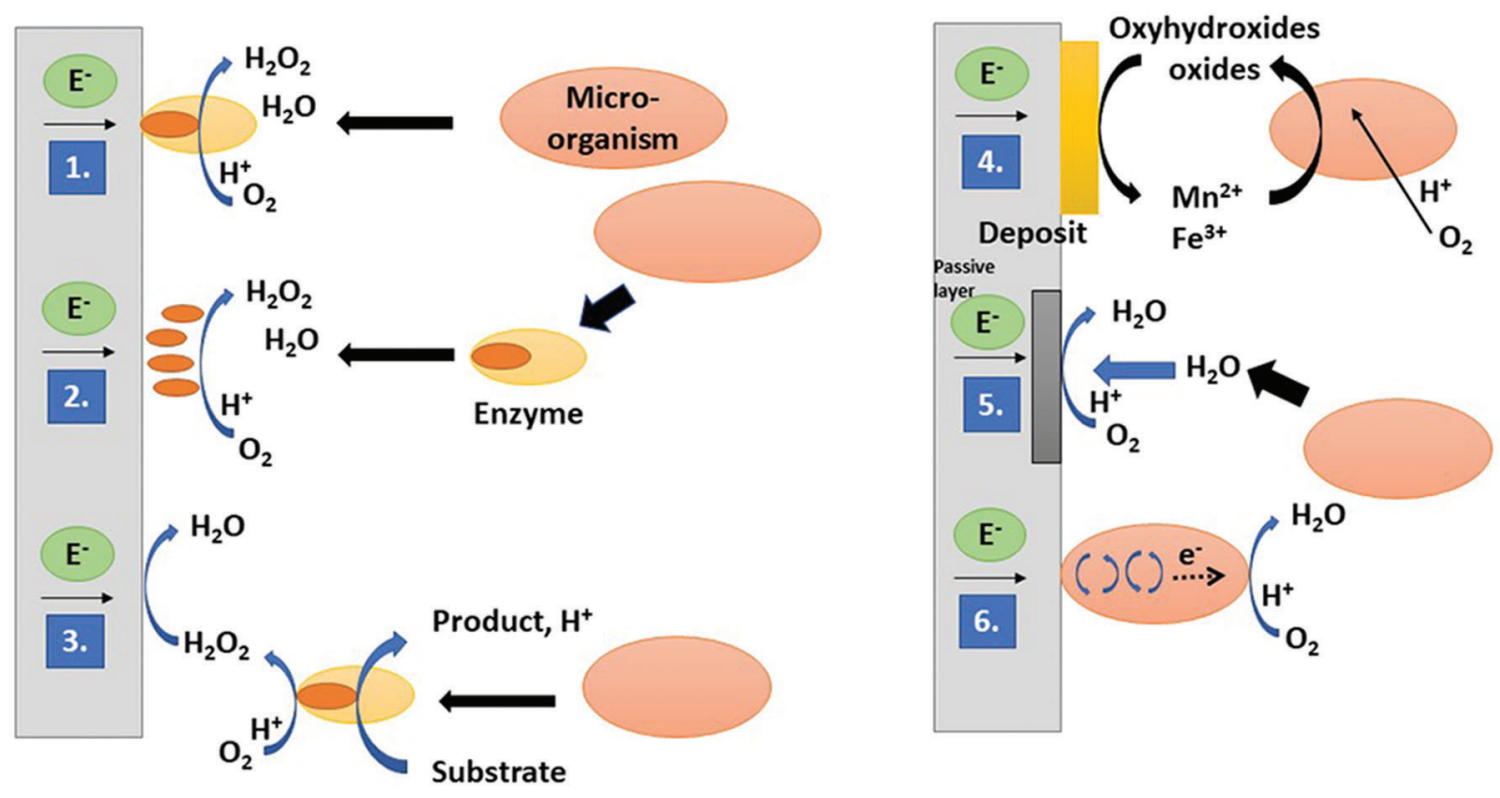

Figure 2: Different microbial catalysis mechanisms of oxygen reduction biofilms (1) Direct catalysis by extracellular adsorbed proteins. (2) Direct catalysis by metal-exopolymer complexes or adsorbed prosthetic groups (porphyrins). (3) Indirect catalysis of hydrogen peroxide and organic acid by enzymes that reduce oxygen. (4) Indirect catalysis mediated by Ferro/manganese bacteria formed by manganese or iron oxides. Oxygen is dissolved by bacteria and iron, or manganese ions are oxidized into oxyhydroxides or oxides which are reduced down to electrode surface ions. (5) The biofilm-producing hydrogen peroxide increases the oxygen-reducing catalytic properties of the stainless-steel oxide layers.

(6) Direct electron transport from the electrode to the bacterial cell 


\subsubsection{Cathode Materials}

In MFCs, cathode efficiency is very important in the production of electricity. The most common cathode reaction is oxygen reduction. The gradual reduction of oxygen on the surface of carbon or graphite electrodes causes a strong overpotential reduction, which is one of the most limiting factors responsible for MFC working. All types of cathode materials, such as air cathodes, underwater aqueous cathodes, and biocathodes, usually use carbon paper, graphite chips, felt, and fabric. Consequently, industrial use of such types of non-catalyzed materials is restricted due to their sluggish cathode reduction kinetics.

\subsubsection{Cathode Surface Area}

The electricity output of the MFCs is limited to the surface area for the cathode. More oxidant-reduction reaction sites are generated, and the cathodic reaction efficiency is improved by the greater cathode surface region. After a certain degree, with an increase in the surface area, the improvement in power output becomes negligible. So, it is appropriate that there will be a more efficient oxidant-reduction site for a huge surface. Inadequate surface area for either carbon paper or graphite layer is a significant restriction encountered by researchers in traditional cathodes. There were several variables in improving the cathode's active surface area. Separate materials have been added to improve the surface area per volume ratio, including woven graphite felt and board, carbon fibre and felt, granular graphite, RVC (Reticulated vitreous carbon), and stainless steel.

\subsubsection{Cathodic Electron Acceptor}

In general, the electron acceptors are oxidants with high redox potential. The application of replacing electron acceptors is one way to decrease the excess potential of the cathodic stimulus. Different types of electron acceptors such as ferricyanide, persulfate, dichromate, permanganate, bleaching paste, and hydrogen peroxide were also more frequently utilized by scientists. Besides that, because of their inability to recover by oxidation with oxygen, the use of such electron acceptors is minimal. Hence, constant renewal is necessary.

\subsubsection{Cathode Catalyst}

The cathode catalysts significantly minimize the energy barrier of activation and improve the kinetics of oxygen elimination at the electrode surface. Extremely active catalysts used to boost the functioning of the MFC system are metal-based catalysts such as platinum (Pt). Platinum has a reasonable low over-potential for oxygen reduction and reaction rate rise. While platinum has outstanding catalytic efficiency, its use is limited by its comparatively high cost and efficiency reduction due to sulfide poisoning. Efforts have been made to fix this problem.

\subsubsection{Cathodic Operational Conditions}

There are very significant considerations in cathodic operating conditions, such as cathode oxidant concentration and catholyte $\mathrm{pH}$. The development of MFCs by both the Nernst equation and reduced reaction kinetics is driven by an increase in the concentration of oxidants in the cathode. Cathode halfcell ability depends on catholyte $\mathrm{pH}$, cathode chamber electron acceptors concentration, the capability of catholyte buffering, temperature, etc. It was confirmed that by increasing the oxidant rate in doublechambered MFCs, improving the decrease in cathode kinetics was verified. Reducing the $\mathrm{pH}$ of the catholyte by adding acid to aerated tap water enhanced the performance of the cathode. Operating temperature also limits cathode efficiency by controlling the kinetics of oxidant reduction, mass reduction, and proton transfer. The application of single-chamber MFC without a membrane has been reported to increase electricity production by $9 \%$ as ambient temperatures rise from 20 to $32^{\circ} \mathrm{C}$ [36]. 


\subsection{Oxygen Reduction Reactions (ORR) in Fuel Cell}

Oxygen reduction reaction (ORR) is the most fundamental mechanism in electrochemistry and electrodialysis due to its limiting reaction to the broad commercialization of fuel cells [37]. Several experiments have been suggested to explain the ORR mechanism, the most common of which is the research proposed by Wroblowa et al. [38], which indicates that oxygen can be reduced by two pathways via adsorption to the electrode; the direct pathway for water formation using four electrons and four protons, as explained by the following reaction:

$\mathrm{O}_{2}+4 \mathrm{e}^{-}+4 \mathrm{H}^{+} \rightarrow 2 \mathrm{H}_{2} \mathrm{O}, \quad \mathrm{E}^{\mathrm{o}}=1.23 \mathrm{~V}$ (vs. SHE)

Another option is the indirect route, which involves the formation of water via the use of hydrogen peroxide as an intermediate, which is subsequently reduced to produce water. The oxygen route is another name for this mechanism.

Partially reducing the generation of hydrogen peroxide

$\mathrm{O}_{2}+2 \mathrm{H}_{2} \mathrm{O}+2 \mathrm{e}^{-} \rightarrow \mathrm{HO}_{2}^{-}+\mathrm{OH}^{-}$

$\mathrm{HO}_{2}^{-}+\mathrm{H}_{2} \mathrm{O}+2 \mathrm{e}^{-} \rightarrow 3 \mathrm{OH}^{-}$

When both reactions (4) and (5) are added together, the result is reaction (1), indicating that the net reaction of both the above-mentioned pathways is similar. It is often noticed that more than the equilibrium potential described above $\left(\mathrm{E}^{0}=1.23 \mathrm{~V}\right)$ is always needed by the ORR. The additional capacity available for the ORR to be implemented is known as overpotential [39]. To minimize the excess potential of ORR, electrocatalysts are used. Overpotential is also an important consideration in evaluating an ORR catalyst's efficacy. The multi-electronic mechanism of ORR is made up of multiple isolated electrons that are connected or uncoupled with elementary proton transfer reactions. Diffusion of the dissolved oxygen present in the solution causes molecular oxygen to be depleted at the electrode surface. In addition, the physicochemical properties of the surface of the catalyst, as well as the ambient environment, decide the pathway of reduction that must be pursued to reduce $\mathrm{O}_{2}$. By producing a corrosive peroxide $\left(\mathrm{H}_{2} \mathrm{O}_{2}\right)$ intermediate, it is often necessary to remove the third pathway for sustainable catalysis. The formation of $\mathrm{H}_{2} \mathrm{O}_{2}$ hinders the process but also deteriorates polymer membrane by generating reactive radicals [38]. Thermodynamic factors, including the variation in free energy throughout the reduction reaction, also affect an electrocatalyst's ORR catalytic performance. The evaluation of free energy changes on the catalyst surface during ORR is critical to the development of a better-performing electrocatalyst in the future [40].

Specifically, the adsorption of intermediates at an electrode surface is responsible for all of the ORR dynamics. On the catalyst surface, it is the adsorption of intermediates such as oxygen $\left(\mathrm{O}^{*}, \mathrm{OH}^{*}\right.$, $\mathrm{OOH}^{*}$ ). Consequently, it is necessary to empirically evaluate the other intermediates in order to regulate the precise reaction process [41]. In this instance, to measure the surface interaction energies with adequate precision, a computational study may be carried out. A density functional theory (DFT) analysis is carried out to determined that oxygen adsorption to the electrode is necessary for the generation of overpotential. When the electrode surface is exposed to a high potential, it is noticed that $\mathrm{O}_{2}$ is substantially adsorbed to it. As a result of the strong adsorption, the transition of protons and electrons to the adsorbed $\mathrm{O}_{2}$ molecule is restricted (Fig. 3). In addition, the binding affinity for different oxygenated species formed during the catalytic action of the catalyst during ORR controls. For effective ORR catalysis, an ideal binding force to the intermediates is, therefore, a necessary criterion. The heavy binding of $\mathrm{O}^{*}$ and $\mathrm{OH}^{*}$, however, restricts the end product's desorption $\left(\mathrm{H}_{2} \mathrm{O}\right)$ and renders the active sites unavailable for more adsorption of $\mathrm{O}_{2}$. A different catalyst has a distinct intermediate binding energy. For the most part, a catalyst's intrinsic binding characteristic relies on its electronic structure [42]. 
High energy metal d-states interact more with intermediates than Fermi energy, indicating that they have a higher interaction with the electrode surface than Fermi energy [43].

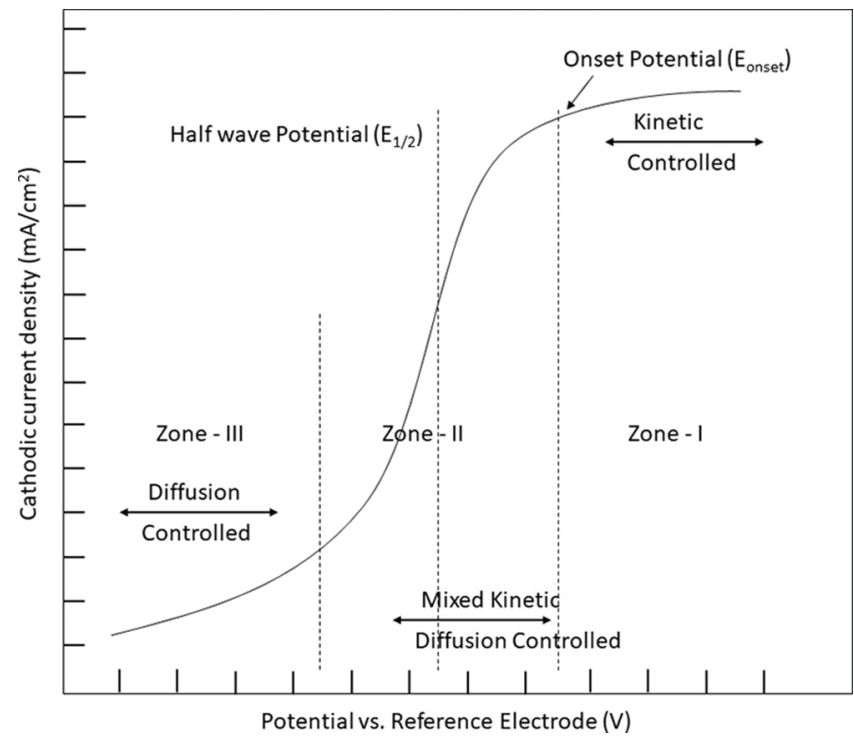

Figure 3: Different characteristics region of ORR polarization plot of a catalyst

\subsection{Non-Oxygen Terminal Electron Acceptors}

Several studies have been carried out to identify an effective e-acceptor for MFC. The power production utilizing potassium ferricyanide is $426 \mathrm{mV}, 181 \mathrm{~mW} / \mathrm{m}^{3}$ which is very high in comparison to dissolved oxygen (DO) $\left(150 \mathrm{mV}, 22.5 \mathrm{~mW} / \mathrm{m}^{3}\right)$. While it is a low cost and strong electron acceptor, it can undergo secondary reactions at low $\mathrm{pH}$, which can result in the production of toxic and hazardous $\mathrm{HCN}$, which is not desirable, see Tab. 1 [44]. According to the findings of Savla et al. [44], the output of powerdependent potassium persulphate is marginally lower than the output of potassium permanganate, depending on the stability of the potassium persulphate. In a separate comparative analysis of the efficiency of persulphate and ferricyanide, it was discovered that after several cycles of operation, persulphate would produce a significant amount of power; As a result, it is possible to argued that persulphate is more likely to be evaluated in the near future. Furthermore, research indicates that improving the efficiency of the terminal electron transfer may enhance the electron intake of both oxygen and non-oxygen terminal electrons [45].

\subsection{Electrochemical Technique for Determining the Figure of Merit of an ORR Catalyst}

The catalytic activity of ORRs is typically measured through the application of a cathode catalyst and compared under comparable conditions with the present condition ORR catalyst Pt [46]. Furthermore, the ORR mechanism is investigated in a typical electrochemical cell using the half-cell reaction. It is necessary to use a thin film catalyst placed on a rotating disc electrode (RDE) or a rotating ring disc electrode (RRDE) in order to conduct the standard half-cell investigation of an ORR catalyst. Using a linear sweep voltammetry process, the cathodic polarization plot is taken in a steady-state or with a known RDE or RRDE rotation Fig. 3 [47]. Three characteristic regions form a standard ORR polarization plot of a catalyst. The first region (Zone I) is known to be the kinetic control area, in which the ORR rate is significantly sluggish, while the cathodic current density increases steadily. It is noticed that the current density increases significantly while at the same time decreasing in the second (Zone II) region, which is a combination of kinetic and diffusion regulated regions. The third (Zone III) region is a diffusion- 
controlled region in which the current density of an electrode is determined via the rate of diffusion of the reagents reaching the moving electrode's surface. Following all the three characteristic regions, the two most significant additional criteria commonly employed for the estimation of catalytic efficiency are onset potential $\left(\mathrm{E}_{\mathrm{onset}}\right)$ and half-wave potential $\left(\mathrm{E}_{1 / 2}\right)$, respectively. The additional optimistic significance of $E_{\text {onset }}$ and $E_{1 / 2}$ indicates the greater catalytic activity of the catalyst. Though, the concept of $E_{\text {onset }}$ varies from paper to paper. Some papers say that $\mathrm{E}_{\text {onset }}$ can reach $5 \%$ of the diffusion-limited current density $\left(\mathrm{J}_{\mathrm{L}}\right)$ [48]. Another description implies that $\mathrm{E}_{\text {onset }}$ is potential when the actual density approaches the threshold value of $0.1 \mathrm{~mA} / \mathrm{cm}^{2}$ [37]. As a result, it is critical to understand the concept of $E_{\text {onset }}$ as it is employed in the ORR catalytic converter analysis and to compare it to the conventional Platinum catalyst under similar conditions [49-53].

Table 1: List of various terminal electron acceptors and their half-cell reactions [44]

\begin{tabular}{|c|c|c|c|c|}
\hline $\begin{array}{l}\text { Electron } \\
\text { acceptor }\end{array}$ & $\mathrm{E}$ & $\mathrm{E}^{0}$ & Cathodic reduction reaction & Reaction conditions \\
\hline $\mathrm{ClO}^{4-}$ & 0.87 & 1.29 & $\mathrm{ClO}^{4-}+8 e^{-}+8 \mathrm{H}^{+} \rightarrow \mathrm{Cl}^{-}+4 \mathrm{H}_{2} \mathrm{O}$ & {$\left[\mathrm{ClO}^{4-}\right]=\left[\mathrm{Cl}^{-}\right], \mathrm{pH}=7$} \\
\hline $\mathrm{Fe}(\mathrm{CN})_{6}{ }^{3-}$ & 0.36 & 0.36 & $\mathrm{Fe}(\mathrm{CN})_{6}^{3-}+e^{-} \rightarrow \mathrm{Fe}(\mathrm{CN})_{6}^{4-}$ & {$\left[\mathrm{Fe}(\mathrm{CN}){ }_{6}{ }^{3-}\right]=\left[\mathrm{Fe}(\mathrm{CN}){ }_{6}^{4-}\right]$} \\
\hline \multirow[t]{2}{*}{$\mathrm{O}_{2}$} & 0.8 & 1.23 & $\mathrm{O}_{2}+4 e^{-}+4 \mathrm{H}^{+} \rightarrow 2 \mathrm{H}_{2} \mathrm{O}$ & $\mathrm{pO}_{2}=0.2, \mathrm{pH}=7$ \\
\hline & 0.33 & 0.69 & $\mathrm{O}_{2}+2 e^{-}+2 \mathrm{H}^{+} \rightarrow 2 \mathrm{H}_{2} \mathrm{O}_{2}$ & $\begin{array}{l}\mathrm{pO}_{2}=0.2,\left[\mathrm{H}_{2} \mathrm{O}_{2}\right]=5 \mathrm{mM}, \mathrm{pH} \\
=7\end{array}$ \\
\hline $\mathrm{MnO}^{4-}$ & 1.1 & 1.7 & $\mathrm{MnO}^{4-}+3 e^{-}+2 \mathrm{H}^{+} \rightarrow \mathrm{MnO}_{2}+2 \mathrm{H}_{2} \mathrm{O}$ & {$\left[\mathrm{MnO}_{4}\right]=5 \mathrm{mM}, \mathrm{pH}=7$} \\
\hline $\mathrm{S}_{2} \mathrm{O}_{8}{ }^{2-}$ & 1.96 & 1.96 & $\mathrm{~S}_{2} \mathrm{O}_{8}^{2-}+2 e^{-} \rightarrow 2 \mathrm{SO}_{4}^{2-}$ & {$\left[\mathrm{S}_{2} \mathrm{O}_{8}{ }^{2-}\right]=\left[\mathrm{SO}_{4}{ }^{2-}\right]=5 \mathrm{mM}$} \\
\hline \multirow[t]{2}{*}{$\mathrm{NO}^{3-}$} & 0.73 & 1.25 & $2 \mathrm{NO}^{3-}+10 e^{-}+12 \mathrm{H}^{+} \rightarrow \mathrm{N}_{2}+6 \mathrm{H}_{2} \mathrm{O}$ & $\begin{array}{l}{\left[\mathrm{NO}^{3-}\right]=5 \mathrm{mM}, \mathrm{pN}_{2}=0.2, \mathrm{pH}} \\
=0.7\end{array}$ \\
\hline & 0.42 & 0.83 & $2 \mathrm{NO}^{3-}+2 e^{-}+2 \mathrm{H}^{+} \rightarrow \mathrm{NO}^{2-}+\mathrm{H}_{2} \mathrm{O}$ & {$\left[\mathrm{NO}^{3-}\right]=\left[\mathrm{NO}^{2-}\right], \mathrm{pH}=0.7$} \\
\hline $\mathrm{Cr}_{2} \mathrm{O}_{7}^{2-}$ & 0.42 & 1.36 & $\mathrm{Cr}_{2} \mathrm{O}_{7}^{2-}+6 e^{-}+14 \mathrm{H}^{+} \rightarrow 2 \mathrm{Cr}^{3+}+7 \mathrm{H}_{2} \mathrm{O}$ & $\begin{array}{l}{\left[\mathrm{Cr}_{2} \mathrm{O}_{7}^{2-}\right]=\left[\mathrm{Cr}^{3+}\right]=5 \mathrm{mM}, \mathrm{pH}} \\
=7\end{array}$ \\
\hline $\mathrm{Cu}^{2+}$ & 0.27 & 0.34 & $C u^{2+}+2 e^{-} \rightarrow C u(s)$ & {$\left[\mathrm{Cu}^{2+}\right]=5 \mathrm{mM}$} \\
\hline $\mathrm{VO}_{2}{ }^{2+}$ & 0.17 & 1.00 & $\mathrm{VO}_{2}^{2+}+2 e^{-}+2 \mathrm{H}^{+} \rightarrow \mathrm{VO}^{2+}+\mathrm{H}_{2} \mathrm{O}$ & {$\left[\mathrm{VO}_{2}{ }^{2+}\right]=\left[\mathrm{VO}^{2+}\right], \mathrm{pH}=7$} \\
\hline
\end{tabular}

\section{Various Cathode Catalysts for ORR Improvement}

The oxygen reduction reaction is considered as an electrochemical effect resulting in a substantial energy loss. Furthermore, for most catalysts, the high standard reduction potential, i.e., $1.23 \mathrm{~V} v s$. SHE, is the most significant restraint on the ORR reaction, which is the primary limiting factor. With the exception of a few noble metals, the majority of materials are reactive at high potential, which limits their application. Pt leads a $4 \mathrm{e}-\mathrm{ORR}$ route with less $\mathrm{H}_{2} \mathrm{O}_{2}$ production than other noble metals, according to the electrocatalytic analysis carried out with several noble metals like $\mathrm{Au}, \mathrm{Cu}, \mathrm{Pt}, \mathrm{Hg}, \mathrm{Ag}, \mathrm{Pd}$, and so on [45].

Composite catalysts made of non-precious metals, carbon-based, conductive polymers and biocathodes have drawn tremendous interest from the scientific community due to their low synthesis costs and simple availability. As a result, several studies focusing on the production of these ORR catalysts for MFCs as illustrated in Fig. 4, Tab. 2 and also various generations of ORR catalysts have been described in Fig. 5. 


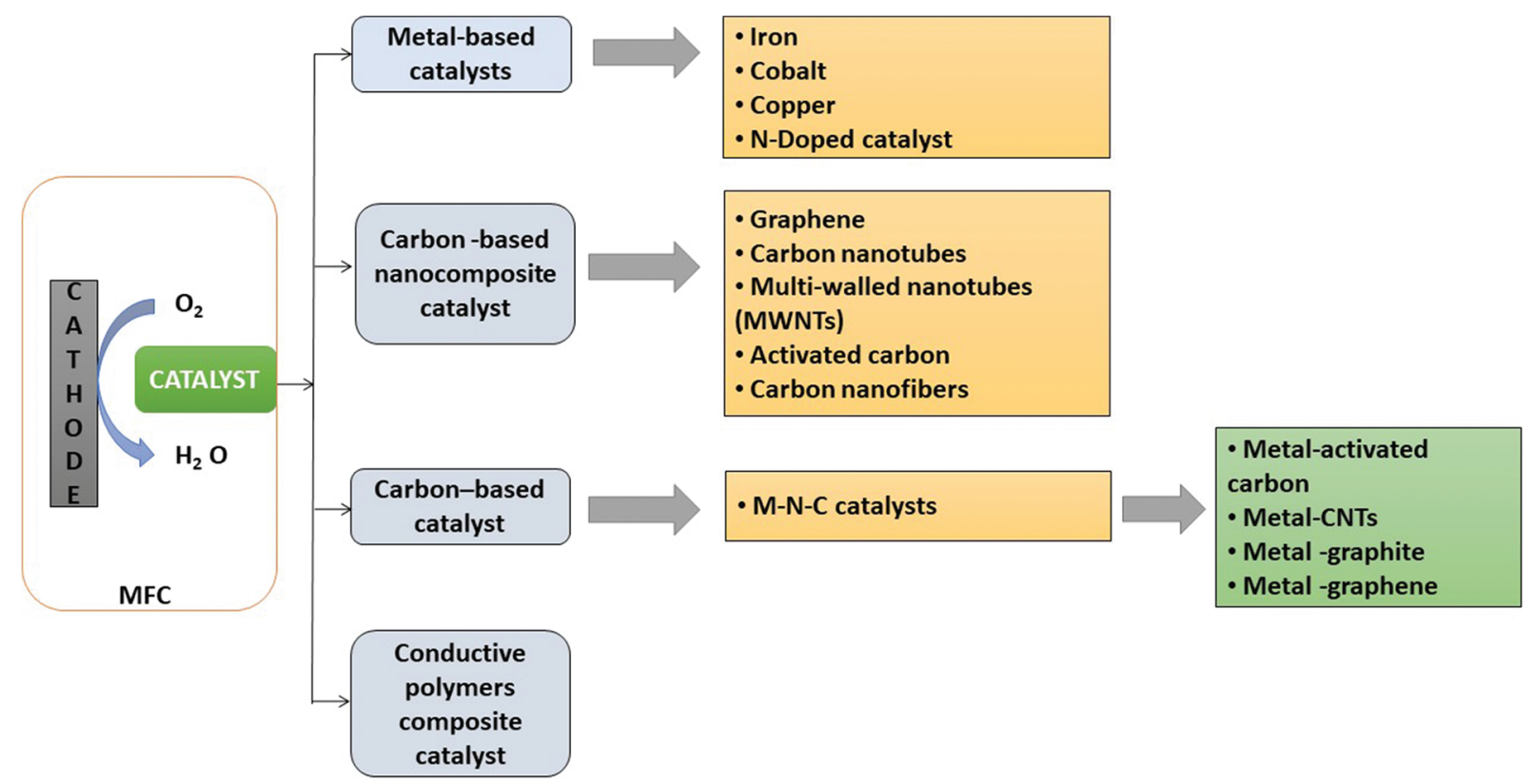

Figure 4: Schematic representation illustrating several oxygen reduction catalysts

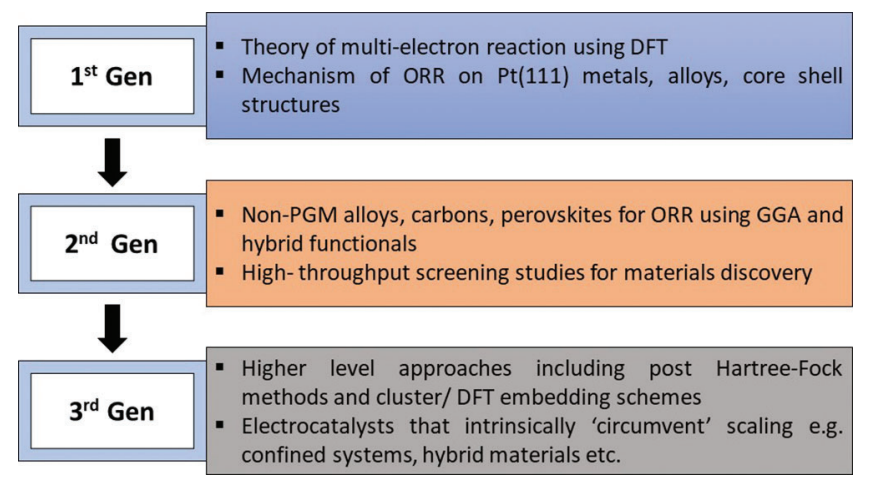

Figure 5: Various generations of ORR catalysts

\subsection{Metal-Based Catalysts}

Transition metals are well known to have ORR catalytic activity. Several studies have indicated that the metal oxides on carbon support have wide applications for low-temperature fuel cells as Pt free cathode catalysts due to their low cost, plentiful design, and excellent ORR activity. Different metal-based catalysts have been clarified below.

\subsubsection{Iron}

Iron was studied in the form of composites and tested for power generation in various MFCs. The maximum power density of $68-80 \mathrm{~mW} / \mathrm{cm}^{2}$ at $\mathrm{pH} 11$ was obtained by the cathodes in double chamber MFCs based on Fe-AAPyr (aminoantipyrine) and Fe-MBZ (mebendazole) [54]. The Fe-AApyr, a catalyst-free ORR from any Platinum Group Metal (PGM), has been shown to have the highest power and can greatly improve the MFC's efficiency. The Iron and Amino Precursor Antipyrin (Fe-AAPyr) was prepared by the Sacrificial Support System (SSM) [55], based on iron, cobalt, nickel, and manganese. In addition, with low charge transfer, low activation barrier, and higher exchange current density [56], this 
modified AC showed excellent ORR activity. In an associated study, the Fe-Mn-AAPyr (Iron, manganese and amino precursor antipyrin) catalyst possessed the maximum output power among other bimetallic catalysts comprising PGM-free metal that were prepared by the SSM [57]. Catalysts formed from a physical mixture of graphene nanosheets and a Fe-AAPyr catalyst in the cathode, which breaths air, resulted in power generation of $235 \pm 1 \mathrm{~mW} / \mathrm{cm}^{2}$ [58]. In comparison, the Fe-AAPyr catalyst provided an apex power to surface area ratio of up to $1.3 \mathrm{~W} / \mathrm{m}^{2}$ in sewage slugged microbial cells [59]. The power density (PD) of Fe-AAPyr achieved in RRDE swung was in the centre of $90 \pm 9 \mu \mathrm{W} / \mathrm{cm}^{2}$ and $262 \pm 4 \mu \mathrm{W} / \mathrm{cm}^{2}$ with $0.1 \mathrm{mg} \mathrm{cm}^{-2}$ (lowest) and $10 \mathrm{mg} \mathrm{cm}^{-2}$ (highest) catalyst loaded individually [60]. An iron catalyst chelated with some ligands constructed by thermolysis of EDTA [pyrolyzing carbon mixed iron-chelated ethylenediaminetetraacetic acid] (PFeEDTA/C) provided a PD of $1122 \mathrm{~mW} / \mathrm{m}^{2}$ and remained stable for 31 days [61]. It has been observed when porous carbon obtained from asphalted petroleum was doped with Fe-N, an excellent ORR output due to rich carbon porosity, massive precise surface area, and Fe-N doped carbon [62]. Fe-Ricobendazole demonstrated a power density of $195 \mu \mathrm{Wcm}^{-2}$ and a 55-fold reduction in cost compared to Pt [63]. Another research stated that an ironbased cathode, deposited FePc (Iron II phthalocyanine) on two dissimilar carbon compounds (carbonaceous) by an iron-based cathode synthesized using a classical non-pyrolysis technique. The resulting materials were positioned in a cathode air-producing arrangement by ORR in an impartial environment [64]. In a related study, FePc-MnOx combined air-cathode catalyst produced more power than the $\mathrm{Pt} / \mathrm{C}$.

\subsubsection{Cobalt}

The Cobalt-macrocyclic complex has been observed to increase catalyst dispersion and ORR kinetics consequently generated the maximum electrical power density of $64.6 \mathrm{~mW} / \mathrm{m}^{2}$ [65]. The cobalt oxide/nano-carbon hybrid material coated air-cathode resulted in a maximum power density $\left(\mathrm{P}_{\max }\right)$ of $17 \mathrm{~mW} / \mathrm{m}^{2}$, which was reported approximately 5.3 times higher than the value of nitrogen-doped carbon nanotubes (NCNT) based cathode containing MFC. These compounds acted as stellar ORR catalysts at pH 7 owing to their versatile form, strength, conductivity, and surface area contributed to efficiency [66]. On the other hand, the performance of a $\mathrm{Co}_{3} \mathrm{O}_{4} / \mathrm{NCNT}$ cathode decayed very little in 16 cycles, indicating the outstanding stability of these MFCs [66]. An air cathode catalyst was synthesized using insitu electro-deposition of $\mathrm{NiCo}_{2} \mathrm{O}_{4}$ nanoplatelets on carbon cloth. Owing to its low internal resistance, its maximum power density was observed $12.96 \%$ higher than the $\mathrm{Pt} / \mathrm{C}$ catalyst [67]. CoTTP ([meso-tetrakis (2-thienyl) porphyrinate] $\mathrm{Co}(\mathrm{II})$ ) cathodes of MFCs successfully treated wastewater containing up to $0.04 \mathrm{M}$ methanol in a single chamber and demonstrated higher methanol resistance $(>0.02 \mathrm{M})$ than $\mathrm{Pt}$ cathodes [68]. In this study, the incorporation of cobalt oxide increased iron phthalocyanine's ORR activity. The highest power density of $654 \pm 32 \mathrm{~mW} / \mathrm{m}^{2}$ was obtained by the C-CoOx-FePc cathode, and even after 50 cycles, the voltage output of the MFC was almost constant, indicating strong potential for long-term robustness [33]. In a separate experimental study, Co-FePc/CDC (carbide-derived carbon) was synthesized from waste rods after heating a high-temperature furnace, further, It was applied to the cathode, and as a result, a maximum production power of $1.57 \mathrm{~W} / \mathrm{m}^{2}$ was attained at its peak [69]. Geobacter sulfurreducens fed anode with RuCoSe (ruthenium-cobalt-selenide) air cathode was used to convert acetate to electricity-a peak PD was reached which was comparable to $\mathrm{Pt}$ [70]. Wastewater treatment by MFCs with $\mathrm{NaCo}_{2} \mathrm{O}_{4}$ cathode generated PD and current density of $0.6 \mathrm{Wm}^{-2}, 3 \mathrm{Am}^{-2}$, respectively [71].

\subsubsection{Copper-Based Catalysts}

Copper composites have been studied recently as an ORR catalyst for MFCs. In single-chamber MFC, $\mathrm{Cu}$ and graphene oxide were tested as $\left(\mathrm{Cu}_{2} \mathrm{O} / \mathrm{rGO}\right)$ a cathode catalyst which demonstrated the results in terms of OCV $0.223 \mathrm{~V}, 92.5 \%$ Coulombic efficiency compared to $0.206 \mathrm{~V}$ and $90.0 \% \mathrm{Pt} / \mathrm{C}$ cathode, respectively. 
Strong ORR kinetics was observed due to improved diffusion of $\mathrm{O}_{2}$ to the surface of the cathode [72]. In another study, bacterial cellulose was doped with phosphorus and copper through freeze-drying and hightemperature pyrolysis to prepare a cathode catalyst. Due to copper and phosphorous doping, more active sits were induced in bacterial cellulose pores, and catalytic activity was consequently increased. The increase in catalytic sites results in a high power density and current density of $1177.31 \mathrm{~mW} / \mathrm{m}^{2}$ and $6.73 \mathrm{~A} / \mathrm{m}^{2}$, respectively, higher than those of $\mathrm{Pt}\left(1044.93 \mathrm{~mW} / \mathrm{m}^{2}\right.$ and $\left.6.02 \mathrm{~A} / \mathrm{m}^{2}\right)$ [73]. Polyaniline and copper have been shown to function synergistically for the oxygen reduction reaction [74]. Carbon paper/ copper polyaniline $(\mathrm{CP} / \mathrm{PANI}-\mathrm{Cu})$ was prepared and utilized as the cathode in one previous experiment. The heavy adhesion of PANI to carbon paper and $\mathrm{Cu}$ to the top of the PANI layer enables higher ORR operation. CP/PANI-Cu cathode showed a maximum current density of $0.50 \mathrm{~mA} / \mathrm{cm}^{2}$ compared to 0.35 $\mathrm{mA} / \mathrm{cm}^{2}$ of the $\mathrm{Pt} / \mathrm{C}$ cathode. The use of copper-barium $(\mathrm{Cu}-\mathrm{B})$ catalysts in MFCs investigated for the treatment of wastewater. The system was capable of high COD removal with $4.1 \mathrm{~mW}$ of power generation, although the magnitude of power output was low, nevertheless, it is sufficient to make the process sustainable as output energy could be utilized for reactor aeration [75].

The previous experiment also demonstrated that the Nafion membrane attached to the CP/PANI-Cu was much less biofouled than the Pt/C cathode [74]. It has been found that the MFC cathode biofilm formation in presence of $\mathrm{Cu}_{2} \mathrm{O}$ was significantly lower than that with $\mathrm{Pt} / \mathrm{C}$ due to the antibacterial properties of copper oxide, which could free up more ORR catalytic side of the cathode, effectively improving the overall efficiency of the MFCs [72]. Similar study was conducted by preparing a cathode catalyst utilizing nitrogenous mesoporous carbon coated with $\mathrm{Co}$ and $\mathrm{Cu}$ nanoparticles achieving the maximum power density of $2033 \mathrm{~mW} / \mathrm{m}^{2}$. The elevated performance was due to $\mathrm{Co}, \mathrm{Cu}$, and pyridinic- $\mathrm{N}$, which culminated in the exposure of more active sites, eventually resulting in enhanced ORR performance. A facile one-step hydrothermal process was employed to develop low-cost cathode catalysts, a hybrid of CNTs with $\mathrm{Cu}-\mathrm{Se}$ nanoparticles (CuSe-CNTs). The catalyst with equivalent parts of $\mathrm{CuSe}$ and CNTs (ratio 1:1 of the different mass ratios tested of CuSe-CNTs displayed a higher power density of $425.9 \pm$ $5 \mathrm{~mW} / \mathrm{m}^{2}[76]$.

The addition of polyvinylpyrrolidone (PVP) as a surfactant in a single-step electrodeposition process contributed to the development of a strongly ordered porous hydrangea-like $\mathrm{Cu}_{2} \mathrm{O}$ structure on activated carbon. The optimized catalyst recorded a maximum power density of $1610 \pm 30 \mathrm{~mW} / \mathrm{m}^{2}$. The PVPassisted method led to the formation of active C-N sites, surface functional groups and $\mathrm{O}_{2}$ vacancies, resulting in lower activation barriers, low transfer resistance and high current exchange density [77].

\subsubsection{N-Doped Catalysts}

Nitrogen-doped partially graphitized carbon (NPGC) catalysts achieved a maximum power density of $1122 \mathrm{~mW} / \mathrm{m}^{2}$ and displayed a decrease in efficiency only after 80 days, giving it a promising candidate for use in MFCs [78]. Iron-activated nitrogen-doped catalytic converter led to a well-decorated wide plane area, interlinked, nanopore catalyst, as well as superbly dispersed Fe-N, live material. Increased ORR operation relative to conventional $\mathrm{Pt} / \mathrm{C}$, yielded more optimistic half-wave potential, excellent methane resistance, high reliability, a much higher maximum power density, and a much longer stable operating period [79]. $\mathrm{N}$-doped $\mathrm{Ag} / \mathrm{Fe} / \mathrm{C}$ catalyst was observed to show better ORR efficiency, a high PD of $1502 \mathrm{~mW} / \mathrm{m}^{2}$ and improved constancy than the conventional Pt/C [80]. In another research, N/Fe-C, where noble $\mathrm{N}-\mathrm{Fe}$ is doped in conductive carbon, was used as an ORR catalyst which enhanced the electrochemically active region, resulting in the highest power density and output voltage by $11 \%$ and $0.72 \%$ respectively, in comparison to the conventional Pt/C catalyst [81]. Fe-PPA has also been studied as a cathode catalyst in MFCs where the overall electron transfer number was found to be 3.55, suggesting that Fe-PAA can be a highly effective low-cost cathode catalyst [82]. When a nitrogen molecule was doped with $\mathrm{MoS}_{2} \mathrm{C}$, the resulting catalyst $\left(\mathrm{N}-\mathrm{MoS}_{2} / \mathrm{C}\right)$ was highly defective but had many energetic sites 
and was highly permeable to oxygen. This, combined with the honeycomb structure, had a maximum PD of $0.815 \mathrm{~mW} / \mathrm{m}^{2}$, far higher than the conventional $\mathrm{Pt} / \mathrm{C}$. Specifically, the synergy between abundant defects and a highly advantageous network leads to the propensity for ORR reactivity [83]. Doping of active sites in Iron/ Cobalt-Nitrogen combined with nano-sized, porous graphene content resulted in a maximum power density of $35 \mathrm{~mW} / \mathrm{cm}^{2}$ compared to $60 \mathrm{~mW} / \mathrm{cm}^{2}$ demonstrated by the conventional Pt/C. The system showed an over-potential of $30 \mathrm{mV}$ comparison to $\mathrm{Pt} / \mathrm{C}$ [84]. The pyrolysis of an organic polymer comprising iron (II) porphyrins has resulted in the creation of porous nitrogen-doped carbon material with encapsulated $\mathrm{Fe}-\mathrm{Nx} / \mathrm{C}$ nanoparticles. It demonstrated greater performance than $\mathrm{Pt} / \mathrm{C}$ at about $20 \%$ higher cell voltage, maximal power density, and Coulombic efficiency [85]. Melamine, an excellent source of nitrogen, was used to synthesize Activated Carbon (AC) doped with nitrogen. The roll-pressed method developed a very dense air cathode using AC catalysts. However, MFCs with AC-N10-900 catalyst generated 65.4\% more electrical output compared to $\mathrm{AC}$, and $11.2 \%$ higher than $\mathrm{Pt} / \mathrm{C}$ with the highest $\mathrm{PD}$ of $1042 \mathrm{~mW} / \mathrm{m}^{2}$. To achieve this $\mathrm{PD}$, the activated $\mathrm{N} / \mathrm{C}$ to melamine ratio was regulated to 10 and $900^{\circ} \mathrm{C}$ pyrolysis temperature [86]. Watermelon rind (WRC-700), which is also an excellent source of nitrogen and a stable precursor, was used to develop a porous carbon nitrogen doped cathode catalyst via pyrolysis at $700^{\circ} \mathrm{C}$. As a result, the developed WRC-700 cathode catalyst achieved a current intensity of $0.19 \mathrm{~mA}$ per unit surface area, which was a peak conversion point attributable to lower resistance of $20.63 \Omega$ relative to $\mathrm{Pt} / \mathrm{C}$ cathode $(37.56 \Omega)$ [87].

A composite catalyst made of carbon black co-doped with $\mathrm{N}_{2}$ and $\mathrm{F}_{2}$ was integrated into a singlechambered MFC air cathode in the study. BP-2000 and poly-tetra-fluoroethylene (PTFE) underwent direct pyrolysis in presence of ammonia for the preparation of BP-N, BP-F catalysts. As BP-NF was used as a cathode catalyst, $\mathrm{P}_{\max }$ was $672 \mathrm{~mW} / \mathrm{cm}^{2}$, relative to $572 \mathrm{~mA} / \mathrm{cm}^{2}$ with $\mathrm{Pt} / \mathrm{C}$ [88]. Three forms of manganese dioxide were tested for MFCs, of which $\beta-\mathrm{MnO}_{2}$ recorded the highest activity due to improved association with CNTs [89]. Increased Mn content of manganese-cobalt (Mn-Co) oxide-based catalysts resulted in increased Brunauer-Emmett-Teller (BET) surface region, resulting in enhanced power generation [90]. A cost-effective solution was suggested by producing electrodes from carbon nanoparticles (CNPs). The CNPs are formed by the deposition on the nano-sized stainless steel (SS) wire disc of the soot collected from incomplete burning fuel on the candle. Research involving physio-chemical and physio-electrical characterization showed that electrode materials should have a graphite structure, rapid water absorption potential, and mechanical and electrochemical stability [91]. A study recorded that a microporous layer prepared with synthetic as well as conductive ink by the amalgamation of $\mathrm{Co}_{3} \mathrm{O}_{4}$ or $\mathrm{Fe}_{3} \mathrm{O}_{4}$ driven the efficiency of oxygen removal to greater than $90 \%$. The resulting MFC worked much better than the Pt catalyst having a volumetric power density (PD) of $6.13 \mathrm{~W} / \mathrm{m}^{3}$ and $21.1 \% \mathrm{CE}$ [92]. Another comparative analysis comparing the activities of $\mathrm{MnCo}_{2} \mathrm{O}_{4}(\mathrm{MCON})$ and $\mathrm{Co}_{3} \mathrm{O}_{4}$ nanorods $(\mathrm{CON})$ showed that $\mathrm{MCON}$ generated power at the highest rate of $587 \mathrm{~mW} / \mathrm{m}^{2}, 29 \%$ higher than power generation by CON [93].

\subsection{Carbon Based Nanocomposite Catalyst}

\subsubsection{Graphene}

Graphene has gained tremendous interest in diverse fields due to the extreme stability in its applications, this section covers a few catalysts based on graphene and compares their efficiency to the conventional Pt/C catalyst. Studies have shown that catalysts of nitrogen-doped graphene $(\mathrm{NG})$ are capable of achieving $\mathrm{P}_{\max }$ equivalent to that of catalyst Pt, suggesting that they could be used as a good substitute in the long term Fig. 6 [94]. Due to numerous active sites and higher surface area, nanotubular alpha- $\mathrm{MnO}_{2} / \mathrm{GO}$ nanocomposites showed fast start-up and strong longevity [95]. A $\mathrm{P}_{\max }$ of $1149.8 \mathrm{~mW} / \mathrm{m}^{2}$ was obtained with iron and nitrogen functionalized graphene (Fe-N-G) [96]. The $\mathrm{P}_{\max }$ of $1159.34 \mathrm{~mW} / \mathrm{m}^{2}$ was achieved by porous $\mathrm{N}-$ doped carbon nanosheet $(\mathrm{PNCN})$ on graphene. Its excellent electrocatalytic activity in ORR was attributed to the high $\mathrm{N}_{2}$ concentration and high specific surface area [97]. Graphene oxide looks like a 
microscopic flower, and it was observed that hybridization with $\mathrm{MgO}(\mathrm{GO} / \mathrm{MgO})$ had a slightly lower cost$2.2 \$ / \mathrm{g}$-than the catalyst for $\mathrm{Pt} / \mathrm{C}(33 \$ / \mathrm{g})$. moreover, its electrochemical activity was greater than that of only an MGO or pure GO cathode [98]. Graphene-like N-doped carbon has demonstrated enhanced catalytic activity since Co-Nx-C, and PtCo nano-alloys have the ability to working no two different materials simultaneously to activate them, creating a chemical reaction between these materials [99]. The highest $\mathrm{PD}$ was 32\% higher than that of conventional $\mathrm{Pt} / \mathrm{C}$ for binder-free nitrogen-doped graphene (NG) sheets. Additionally, its internal resistance was found to be just $20 \%$ of $\mathrm{Pt} / \mathrm{C}$ air-cathode [100]. Boron and a nitrogen-dual-doped graphene sheet (BNG) were produced using a novel technique and used as ORR support for Pt. BNG/Pt interaction has been improved due to remarkable electron-donation by BNG to Pt. In contrast to the conventional $\mathrm{Pt} / \mathrm{C}$, it displayed increased electrocatalytic activity [101]. Composites of nitrogen-doped porous graphene/carbon (NPGC) demonstrated a wide surface area and have high onset potential along with a four-electron ORR pathway, resulting in a more powerful resistance to menthol than $\mathrm{Pt} / \mathrm{C}$ [102]. An rGO, known as reduced graphene oxide was initially developed by removing the oxidized functional group from graphene oxide. The rGO together with nanoparticles of poly (3,4ethylene dioxythiophene) (PEDOT) and iron oxide $\left(\mathrm{Fe}_{3} \mathrm{O}_{4}\right)$ were developed in a tertiary composite catalyst generating the highest PD with a durability of more than $600 \mathrm{~h}$ [103]. Nitrogen and fluorine as codopants for rGO showed enhanced resistance to methanol, long-term stability and highly selective pathways allowing the transition of four electrons [104]. These sheets contain $\mathrm{CoMn}_{2} \mathrm{O}_{4}$ nano-sizedcatalyst dispersed evenly on their surface by applying hydrothermal synthesis on the rGO nanosheets. This synthesis provides a massive BETS (Brunauer-Emmet-Teller Surface) region of $78.4 \mathrm{~m}^{2} / \mathrm{g}$ to the dispersed electro-catalyst and doped with some active sites, such as cobalt (ii) cobalt (iii), manganese (ii), manganese (iii) ions, which are active sites. Consequently, ORR activity and electron transfer rate increased significantly [105]. The highest maximum PD of up to $1956.45 \mathrm{~mW} / \mathrm{m}^{2}$ was achieved by utilizing activated carbon-supported multi-doped graphene [106]. Due to the rotating cathode, the site accessibility of the catalysts was increased and the dissemination of oxygen and $\mathrm{OH}^{-}$ion transfer across the air-cathode was also improved [26]. An innovative method of wastewater treatment to produce $\mathrm{H}_{2} \mathrm{O}_{2}$ is a biomass-based electrochemical system that utilizes the $2 \mathrm{e}^{-}$of the ORR process. As a result, despite the over-oxidation effect, $\mathrm{H}_{2} \mathrm{O}_{2}$ generation efficiency has dramatically increased owing to the improved catalytic action of oxidized graphene containing C-O-C as an oxygen-functional group [107].

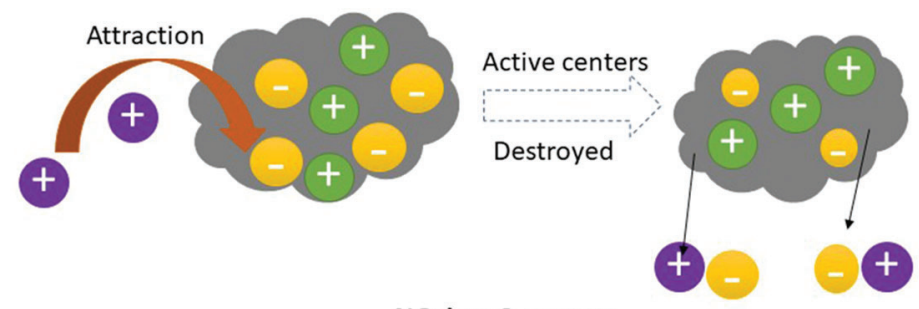

NG: low $O$ content

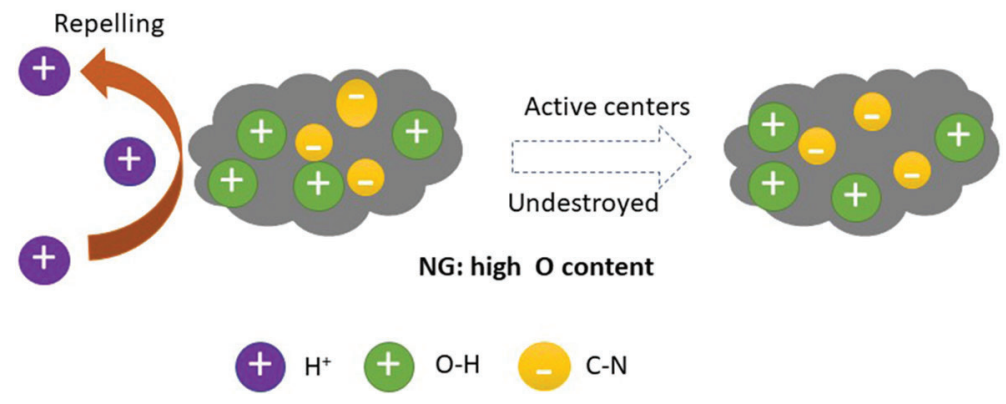

Figure 6: Schematic representation of N-doped graphene in exhibiting ORR activity 


\subsubsection{Carbon Nanotubes (CNTs)}

Poor ORR kinematics in a two-dimensional air-cathode of MFCs limit the efficiency of the system. To improve the electrochemical efficiency as well as maximum power density $\left(\mathrm{P}_{\max }\right)$ in MFCs, nano-sized carbon tubes used to build a 3D structure were found [108]. Composites made of CNTs improved the transition of charge between electrolytes and electrodes, resulting in a $\mathrm{P}_{\max }$ of $24 \mathrm{~mW} / \mathrm{m}^{2}$ [109], whereas manganese dioxide-coated CNTs has been shown to achieve a $P_{\max }$ of $210 \mathrm{~mW} / \mathrm{m}^{2}$ [110]. CNT generated electrical power using palm oil mill effluent sludge as a source of mixed culture as an MFC electrode. In comparison to $\mathrm{Pt} / \mathrm{C}$ (Platinum-Carbon) catalyst, the improved catalytic properties of the $\mathrm{CNT}$ electrode enhanced the ORR mechanism [111]. The electrode-acting bamboo fashioned NCNT (CNT doped with $\mathrm{N}_{2}$ ) demonstrated weaker in-house resistance, better ORR characteristics, and greater power density than the Pt catalyst [112]. Compared to the CC-Pt cathode, a novel CNT derived from the deposition of Pt nanocomposite on the CNT substratum demonstrated higher efficiency of use of the surface area [113].

Application to a stainless-steel mesh electrode with a coating of graphene or CNTs resulted in increased the power density of the MFC, due to lowering of the MFC's internal resistance. The anode and cathode modifications showed an increase in power output of 3-7 and 1.5-4.5 times, respectively, with an enhancement in $\mathrm{P}_{\max }$ by the modified anodes [114]. In the positive half-wave, FePc/CNTs and FePc/PID (polyindole)/CNTs showed higher electricity generation and more potential. Notably, Iron-polyindolecarbon nanotubes (FePc/PID/CNT) displayed a performance equal to that of conventional Pt/C [115]. The nitrogen-doped bamboo-like carbon nanotube (BCNT) has been found to enhance catalytic activity due to high electron transfer numbers. In comparison, it cost 200 times less than $\mathrm{Pt} / \mathrm{C}$ and was competitive [116]. A bifunctional catalyst, $\mathrm{ZnCO}_{2} \mathrm{O}_{4} / \mathrm{N}$-doped-CNT, demonstrated excellent operation, comparable to the efficiency of transition metal catalysts. In several different areas, this novel bi-functional catalyst has the potential for large-scale applications [117]. $\mathrm{N}_{2}$ was found to have a stronger ORR activity when it was doped in CNT. This was transparent and distinct from conventional ORR-activity, as a dopant with a hollow-tube-shaped carbon catalyst. The $\mathrm{CNT} / \mathrm{MoS}_{2}$ carbon nano-sized catalyst derived from $\mathrm{MoS}_{2}$ (molybdenum disulfide nanocomposites) hybridization gave rise to an interlaced structure with abundant $\mathrm{O}_{2}$ chemisorption sites, indicating that electrocatalytic activity was promoted [118]. Co/NCNT nanocomposites are produced by regulated pyrolysis of graphitic carbon nitride and cobalt acetate [119].

\section{Multi-Walled Carbon Nanotubes (MWCNTs)}

Cathodes made of graphite felt (GF) modified multiwalled carbon nanotube (MWCNT), prepared using electrophoretic deposition, were used by microbial sediment fuel cells. The $\mathrm{P}_{\max }$ was detected to be 1.6 times higher that of unmodified graphite felt [120]. Polyaniline (PANI)/MWCNT composites reached a $\mathrm{P}_{\max }$ of $476 \mathrm{~mW} / \mathrm{m}^{2}$ [121]. The composite Co-Se/MWCNT demonstrated better electrochemical efficiency and durability, with the $\mathrm{P}_{\max }$ being much greater than the conventional MWCNT cathode [122].

\subsubsection{Activated Carbon (AC)}

Air cathodes made of activated carbon with a diffusion layer were found to have comparable efficiency depending on their running period (usually 1.5 months). Diffusion layer (DL) AC cathodes with 70\% porosity had the highest power of $1214 \pm 123 \mathrm{~mW} / \mathrm{m}^{2}$, which is greater than the DL containing cathode with $30 \%$ porosity. However, its power decreased by $40 \%$ within a year, suggesting that the porosity of the diffusion layer of AC cathodes can significantly affect the output of power and the long-term stability of AC cathodes [123]. The highest PD was registered by cathodes derived from coal, while peat-based AC showed the top catalytic activities in MFCs. It has been shown that the potential at the beginning of the reaction and the quantity of strong acid have an opposite relationship. The power generation of the MFCs was affected by the presence of functional groups and the diffusion layer of microporous at cathodes. Therefore, based on its highest surface area, the air cathode MFC must not be chosen; instead, 
it must be wisely selected to eliminate the diffusion downsides. This precision can help to generate sites of active catalysts [124]. An experiment showed that a rolling process using rolling activated carbon (AC) could create an inexpensive, binder-metal-free, and versatile air-cathode. To boost regeneration ability and bolster operation, a catalytic layer of PTFE was found [125]. It is generally recognized that the activated carbon air cathode of MFCs is more functional in lowering oxygen and is sustainable for the environment. It was observed that the addition of carbon black to AC exhibited greater current density and low electron flow resistance, and the Pmax of MFCs increased by 9-16\% [124]. Since air cathodes contained activated cobalt-decorated carbon $\left(\mathrm{Co}(\mathrm{OH})_{2} / \mathrm{AC}\right)$, the initial capacity for ORR became 2.6 times higher, while $\mathrm{CO}_{3} \mathrm{O}_{4} / \mathrm{AC}$ with a large surface spot and pore volume was 1.6 times higher and a Pmax of $1420.8 \mathrm{~mW} / \mathrm{m}^{2}$ was obtained [126]. Different Activated carbons (ACs) were treated at different $\mathrm{H}_{3} \mathrm{PO}_{4}$ concentrations. AC-3 treated with $1 \mathrm{M} \mathrm{H}_{3} \mathrm{PO}_{4}$ obtained the peak energy density of $954 \pm 36 \mathrm{~mW} / \mathrm{m}^{2}$ X-ray photoelectron spectroscopy and Boehm titration have shown that MFC efficiency is decreased by the functional groups on the AC acidic surface, such as RCOOR, $\mathrm{RCOOH}$, and $\mathrm{ROH}$. Nanoparticles of Spinel $\mathrm{CoFe}_{2} \mathrm{O}_{4}(\mathrm{CFO})$ on activated carbon with nitrogen as a dopant were created by a method based on an in-situ annealing assembly, carried out in the water at both high temperature and pressure. This catalyst applied on the cathode generated a maximum PD that was 2.39 times greater than that of the control [127]. The maximum $\mathrm{PD}$, stated to be greater than that of catalysts using $\mathrm{Pt} / \mathrm{C}$ as a regular catalytic substance, was increased by $\mathrm{CoO}$ nanosheets assisted by $\mathrm{N}$-doped activated carbon [128].

An excellent, stable catalyst, cobalt, and nitrogen-doped carbon $\mathrm{CoNC}$ was prepared at $900^{\circ} \mathrm{C}$ and showed a PD that was $13.3 \%$ greater than that of $\mathrm{Pt} / \mathrm{C}$. Its microporous structure and pyridinic nitrogencoordinated cobalt contributed to its better performance [129]. In aqueous air cathode MFCs, a flowerlike $\mathrm{Co}_{3} \mathrm{O}_{4}$ catalyst demonstrated improved electrocatalytic activity, increased electron transfer kinetics, greater exchange current rate, and greater maximum power density than the bare cathode [32]. A $\mathrm{P}_{\max }$ of $356 \mathrm{~mW} / \mathrm{m}^{2}$ was obtained by two novel nickel cobaltite-nanocarbon hybrids. In addition, they also showed outstanding environmental stability [130]. Ni/Mn-promoted mesoporous cobalt oxides prepared by an inverse micelle process by one-step wet chemical synthesis demonstrated promising activity for both ORR and (oxygen evolution reaction) OER and better durability than other precious metals [131]. The metal-organic framework (MOF) is a recent and fascinating highly porous composite made from organic connectors and metal ions. To strengthen the cathode output, MOF on activated carbon was found. Although MOF catalysts are inversely affected by chelators, the performance is still better compared to plain AC [132].

Twin metallic substances and a non-metallic substance (nitrogen) were synthesized as a co-dopant for carbon using the pyrolysis method as a class of metal (cobalt)-organic structure based on the M/CoNC catalyst, extremely porous and consistently dispersed with metal as well as nitrogen on a matrix derived from graphite. By providing highly active dense sites, proper regulation of corridors for electronic species, and, essentially, excellent ORR efficiency, the porous and uniformly dispersed $\mathrm{M} / \mathrm{Co} / \mathrm{NC}$ catalyst features energies ORR [133]. The MFCs based on catalysts demonstrated greater durability (110 h operating hours) than the MFCs based on Pt/C (around 40 h) [134]. Its low-cost and environmentally friendly design is the plus side with the only drawback of having high resistance to charge transfer.

A nitrogen-based chitosan can be used as a carbon precursor during the synthesis of activated carbon. Further activation to generate air cathodes is achieved by $\mathrm{KOH}$ with distinct concentrations. It was discovered based on electro-kinematics that the ORR activity specifically depends on the kinetic activity, and thus better kinetic activity induces better ORR activity. Since chitosan is derived from carbon-doped nitrogen, it enhances the activity of ORR Fig. 7 [135]. 


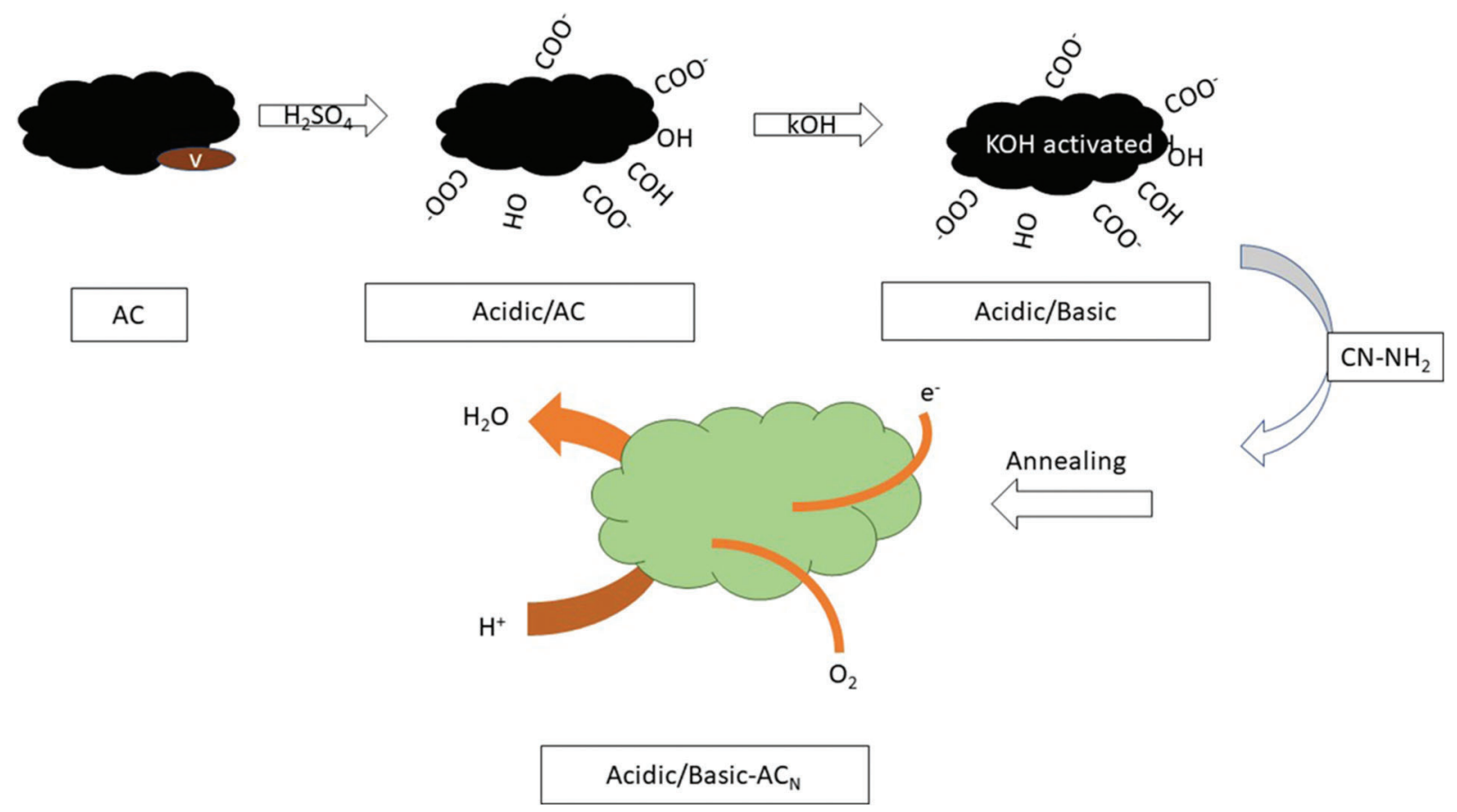

Figure 7: Schematically describing the mechanism of activated carbon in improving ORR activity

\subsubsection{Carbon Nanofibers (CNFs)}

Electrospun carbon nanofibers were activated Via the incorporation of some chemical properties and the treatment of physical properties. Compared to only physically treated activated carbon nanofibers (ACNFs), they displayed a $78 \%$ improvement in power production, and a $16 \%$ increase in power production compared to only chemically treated ACNFs with $4 \mathrm{M} \mathrm{KOH}$. Since the outer surface area of chemically treated CNFs was greater, super catalytic activities were exhibited by these CNFs [136]. By introducing electrospinning at high temperatures, air-cathodes based on graphitic-carbon with metals as dopants have been developed. BCHT, obtained from bamboo branches of Phyllostachys pubescens commonly known as Mazel was synthesized by the pyrolysis process in presence of nitrogen displayed $65 \%$ better power generation in comparison to the conventional electrode material [137]. The ACF (activated carbon fibre) substrate, which was dispersed with $\mathrm{Ni}$, was extracted from $\mathrm{N}-\mathrm{Ni}-\mathrm{CNF} / \mathrm{ACF}$, and $\mathrm{Ni}$ possessed $\mathrm{N}$ as an in-situ dopant material. The preparation of N-Ni-CNF/ACF was chemically carried out using vapor deposition. Its use as an electrode for electricity generation in an MFC demonstrated the highest efficiency by double the PD of non-dopant N-Ni-CNF/ACF [138]. On the other hand, nitrogen-doped CNFs (N-CNFs) demonstrated greater conductivity upon treatment at $900^{\circ} \mathrm{C}$ nitrogen as an in-situ dopant material nitrogen defects and a wider outer surface were thus contained in the prepared catalyst [139]. In this study, the manufacturing process of CNFs composite that carry dual catalytic activities and capacitance characteristics is described. The association of fiber aggregates and the electrode thorn-like structure made the CNFs the strongest high-conductivity catalyst and PD [140].

\subsection{Metal Composites}

\subsubsection{Metal Oxides}

Metal oxides (MO) are generating a lot of interest as a low-cost alternative to platinum/cadmium in MFCs. The ease with which MO-based catalysts may be synthesized, their cost-effectiveness, their good ORR performance, and their ecological tolerance are the primary aspects that urge the researchers to 
utilize Metal oxide - based ORR catalysts. As a cathode catalyst in MFCs, manganese oxides (MnOx) have been extensively investigated because of its inexpensive cost, great abundance, and wide range of oxidation states. When it comes to controlling the activity of MO-based electrocatalysts, morphology, crystal structure, and exact surface area are all important factors to consider. Catalytic activity is also impacted by the chemical structure of the catalyst. Among the different $\mathrm{MnOx}$ that perform ORR operations in the following order: $\mathrm{Mn}_{5} \mathrm{O}_{8}<\mathrm{Mn}_{3} \mathrm{O}_{4}<\mathrm{Mn}_{2} \mathrm{O}_{3}<\mathrm{MnOOH}, \sim \mathrm{MnO}_{2}$. The $\alpha-\mathrm{MnO}_{2}$ nanotubes generated a $\mathrm{P}_{\max }$ of $2100 \mathrm{~mW} / \mathrm{m}^{2}$ which is comparatively higher than $\alpha-\mathrm{MnO}_{2}$ nanorods that generated $1850 \mathrm{~mW} / \mathrm{m}^{2}$ indicating the essentiality of morphology. High surface area and precise microporosity of the ORR were shown to be responsible for the improved catalytic activity, which provided a large number of active sites for the reaction.

\subsubsection{Metal Carbides}

Metal carbides (MCs) are considered to be an important class of materials for fuel cell implementation due to their great chemical and physical stability, as well as their resistance to corrosion throughout electrochemical operations. There are numerous advantages of MCs over metals in terms of catalytic activity, selectivity, and tolerance to contamination, among other things. MCs, on the other hand, can produce a wide range of chemical compositions of $\mathrm{MxCy}$ through a variety of electrocatalytic reactions. Consequently, it is necessary to choose the composition in order to maximize the activity of the ORR [45].

\subsection{Carbon-Composites}

MNC (Metal-Nitrogen-Carbon) was porous nitrogen (diameters between 2 and $50 \mathrm{~nm}$ abundant carbon) commonly known as mesoporous nitrogen-rich carbon catalyst synthesized at various temperatures had been explored for application in MFCs. After thirty days of action, the highest PD declined by $11 \%$ for Pt Catalyst in MFCs, whereas a 7\% decrement was observed for the MNC catalyst in MFCs. As a result, the MNC catalyst was considered a low-cost catalyst in MFCs to generate electrical output power and treat wastewater [141]. A fast, one-step microwave-assisted hydrothermal synthesis of reduced graphene oxide produced $(\mathrm{rGO}) / \mathrm{SnO}_{2}$ nanocomposites. The $(\mathrm{rGO}) / \mathrm{SnO}_{2}$ can be used as ORR-catalyst as it shows excellent electrochemical behavior [142]. The CuSe is a dual compound comprised of copper and selenium, commonly known as klockmannite, which possessed a hexagonal nano-sized structure. This black-coating deposited on the rGO-CNTs has been prepared by a low-cost, effective method. The MFCs that were run with that cathode (CuSe-rGO-CNTs) showed a massive energy output compared to the traditional Pt/C [143]. Through an innovative, one-step process, crossed CNTs adorned with klockmannite NPs were formulated. Various mass ratios of (CuSe: CNTs) were examined. The (1:1) ratio exhibited the best ORR activity and a higher power density [144]. Iron and nitrogen as dopant materials for carbon xerogel (CX) were sufficient in producing a suitable catalyst for MFCs. A suitable catalyst was produced by modifying $\mathrm{CX}-\mathrm{N}-\mathrm{Fe}$ with GO (graphene oxide). It was observed a biofilm on the electrode surface when bacterial cells are colonized at the anode. The PD of the newly generated electrode with biofilms is $26.8 \%$ higher than the plain graphite electrode [145]. Nevertheless, a hybrid of $10 \% \mathrm{GO}$ and $\mathrm{MnO}_{2}$ utilizing as a catalyst at cathode generated the highest $148.8 \mathrm{~mW}$ per unit area showing the greatest performance among other concentrations of GO [30].

\subsection{Conductive Polymers Composite Catalyst}

Conductive polymers (CPs) have recently been studied for several applications. These materials are distinguished from many others by their high electrical conductivity as well as their environmental stability. The stability and practical implementation of electrode processing with conductivity polymers provide an enormous possibility to develop systems that are suitable for industrial application. Among the several CPs tested, PANI, polypyrrole (PPy), poly(3-methyl)thiophene (PMeT), and poly(3,4-ethylene dioxythiophene) (PEDOT) were shown to be highly effective ORR catalysts, as was PEDOT. The cumulative electrochemical catalytic activity of these conductive polymer composite materials shift to a 
non-negative potential, leading to the maximum current density. A modified electrode was prepared from prussian blue/polyaniline (PB/PANI) and its power production potential was explored after using this newly produced electrode in the MFCs. The gradual increase in the concentration of PB/PANI on the cathode demonstrated reasonable electrochemical catalytic activity and dramatically increased ORR activity [146]. Despite the poor interactivity between b-type Manganese-di-oxide and granular PANI on the surface, the greater surface area and higher PANI conductivity increased the ORR and PD activity [147]. Using a non-aqueous solution and heat process, a revolutionary Manganese-polypyrrole-carbon nanotube (Mn-PPY-CNT) formulation was developed, producing high dexterity and durability with the maximum PD compared to MFCs using the standard platinum catalyst [148]. To promote biocathode, especially in comparison to the expensive, precious metallic catalyst, microorganisms- for ORR were allowed the MFC a low-cost and equivalent power production. Importantly, as a cathode, the highly conductive and biocompatible polymer composite material will induce and increase biocatalytic activity [149]. RVCs (Reticulated Vitreous Carbons) is a substitute doping material utilized for cost-effective catalysts, such as PANI, PANI-FePc, and PANI-CUPc were used to obtain the highest PD and highest potential [150]. The catalyst's durability plays a crucial role in regulating the MFC's efficiency. Cobaltchelated polyaniline is known as a source of nitrogen and carbon. N-doped with partially graphitized carbon (PGC) $\mathrm{CO} / \mathrm{Co} 9 \mathrm{~S} 8$ catalysts are formulated utilizing this source demonstrating a very low internal resistance [151]. PANI- $\mathrm{MnO}_{2}$ nanocomposites were developed using a single-step, self-originated polymerization method primarily based on a chemical oxidation reaction. Compared to carbon paper, an improved maximal PD was obtained using this cathode at MFC [152]. Using the above process, nanocomposite CNT/PPy was formulated and evaluated in MFCs as a revolutionary cathode catalyst. On both processes, the COD elimination was greater than $80 \%$, which indicating that the CNT/PPy shows outstanding ability as a cathode catalyst [153]. Hierarchical multi-walled $\mathrm{MnO}_{2} /$ polypyrrole $/ \mathrm{MnO}_{2}$ nanotubes (NT-MPMs) were developed by a process that took place at some higher temperatures in water and wreathed with the carbon-cloth anode to increase the ability of power generation of the MFCs. Compared to the carbon-cloth free cathode, this cathode at MFCs displayed a higher efficiency and produced 1.3 times greater potential for power output and had much greater longevity. For more effective electrocatalysis, NT-MPM cathodes have provided special active centres for bacteria as a part of biocathode [154].

Table 2: Types of cathode catalysts and their performance in MFC

\begin{tabular}{|c|c|c|c|c|}
\hline $\begin{array}{l}\text { Type of cathode } \\
\text { catalyst }\end{array}$ & Cathode catalyst & Example & Power density & Reference \\
\hline \multirow[t]{7}{*}{ Carbon-based catalyst } & Graphene & N-doped carbon nanosheet & $1159.34 \mathrm{~mW} / \mathrm{m}^{2}$ & {$[97]$} \\
\hline & & $\mathrm{Fe}-$ and $\mathrm{N}$-functionalized graphene & $1149.8 \mathrm{~mW} / \mathrm{m}^{2}$ & [96] \\
\hline & Carbon nanotube & Manganese dioxide-coated CNTs & $210 \mathrm{~mW} / \mathrm{m}^{2}$ & {$[110]$} \\
\hline & $\begin{array}{l}\text { Multi-walled nanotubes } \\
\text { (MWNTs) }\end{array}$ & Polyaniline (PANI)/MWNT composites & $476 \mathrm{~mW} / \mathrm{m}^{2}$ & {$[121]$} \\
\hline & Activated carbon (AC) & Diffusion layer (DL) AC cathodes & $1214 \pm 123 \mathrm{~mW} / \mathrm{m}^{2}$ & [123] \\
\hline & & $\mathrm{Co}_{3} \mathrm{O}_{4} / \mathrm{AC}$ & $1420.8 \mathrm{~mW} / \mathrm{m}^{2}$ & [126] \\
\hline & & Two novel nickel cobaltite-nanocarbon hybrids & $356 \mathrm{~mW} / \mathrm{m}^{2}$ & {$[130]$} \\
\hline Carbon-based composite & & $10 \% \mathrm{GO}$ and $\mathrm{MnO}_{2}$ & $\begin{array}{l}148.8 \mathrm{~mW} / \mathrm{unit} \\
\text { area }\end{array}$ & {$[30]$} \\
\hline \multirow[t]{2}{*}{ Metal-based catalyst } & Iron & Fe-AAPyr & $90 \pm 9 \mu \mathrm{W} / \mathrm{cm}^{2}$ & {$[60]$} \\
\hline & & $\mathrm{Fe}-\mathrm{N} / \mathrm{AC}$ & $1092 \mathrm{~W} / \mathrm{m}^{2}$ & [155] \\
\hline
\end{tabular}




\begin{tabular}{|c|c|c|c|c|}
\hline \multirow{2}{*}{$\begin{array}{l}\text { Type of cathode } \\
\text { catalyst }\end{array}$} & \multirow[t]{2}{*}{ Cathode catalyst } & \multirow{2}{*}{$\begin{array}{l}\text { Example } \\
\text { Fe-Ricobendazole }\end{array}$} & \multirow{2}{*}{$\begin{array}{l}\text { Power density } \\
195 \mu \mathrm{W} / \mathrm{cm}^{2}\end{array}$} & \multirow{2}{*}{$\begin{array}{l}\text { Reference } \\
{[63]}\end{array}$} \\
\hline & & & & \\
\hline & \multirow[t]{3}{*}{ Cobalt } & Co-naphthalocyanine (CoNPc) & $64.6 \mathrm{~mW} / \mathrm{m}^{2}$ & {$[65]$} \\
\hline & & cobalt oxide/nano-carbon hybrid & $17 \mathrm{~mW} / \mathrm{m}^{2}$ & {$[66]$} \\
\hline & & Co $\left(\mathrm{NO}_{3}\right)_{2}+$ carbon black $(\mathrm{CB})$ & $1540 \mathrm{~mW} / \mathrm{m}^{2}$ & {$[26]$} \\
\hline & \multirow[t]{2}{*}{ Copper } & CuSe-CNTs & $425.9 \pm 5 \mathrm{~mW} / \mathrm{m}^{2}$ & {$[76]$} \\
\hline & & $\mathrm{CP} / \mathrm{PANI}-\mathrm{Cu}$ & $0.50 \mathrm{~mA} / \mathrm{cm}^{2}$ & {$[75]$} \\
\hline & \multirow[t]{3}{*}{$N$ - Doped catalysts } & $\begin{array}{l}\text { Nitrogen-doped partially graphitized carbon } \\
\text { (NPGC) }\end{array}$ & $1122 \mathrm{~mW} / \mathrm{m}^{2}$ & {$[78]$} \\
\hline & & N-Doped $\mathrm{Ag} / \mathrm{Fe} / \mathrm{C}$ & $1502 \mathrm{~mW} / \mathrm{m}^{2}$ & {$[80]$} \\
\hline & & $\mathrm{N}-\mathrm{MoS}^{2} / \mathrm{C}$ & $0.815 \mathrm{~mW} / \mathrm{m}^{2}$ & [83] \\
\hline \multirow{3}{*}{\multicolumn{2}{|c|}{ Conductive polymer composites catalyst }} & $\mathrm{V}_{2} \mathrm{O}_{5} / \mathrm{PANI}$ & $79.26 \mathrm{~mW} / \mathrm{m}^{2}$ & {$[45]$} \\
\hline & & $\mathrm{MnO}_{2} / \mathrm{PANI}$ & $37.6 \mathrm{~mW} / \mathrm{m}^{2}$ & \\
\hline & & $\mathrm{MnFe}_{2} \mathrm{O}_{4} / \mathrm{PANI}$ & $6.49 \mathrm{~W} / \mathrm{m}^{3}$ & \\
\hline \multirow{2}{*}{\multicolumn{2}{|c|}{ Biocathode }} & Acinetobacter sp. & $24 \mathrm{~mW} / \mathrm{m}^{2}$ & \\
\hline & & Sphingobacterium sp. & $49 \mathrm{~mW} / \mathrm{m}^{2}$ & \\
\hline
\end{tabular}

\subsection{Biocathode}

Biocathode has some excellent benefits in contrast to abiotic-cathode MFCs. Firstly, the abiotic cathode has either an unsustainable cathode system, including such potassium ferricyanide or a comparatively costly oxygen-reduction platinum cathode. The latter quickly suffer from poisoning agents (e.g., chloride) and induces secondary contamination. However, as a biocatalyst, biocathode consist of microorganisms having the ability to self-renew and avoid damage from harmful substances. The biocathode is both costeffective and environmentally friendly. Secondly, it offers the possibility of oxidation of different contaminants, in particular nitrogen elimination, owing to the varied and complicated respiratory pathways of microorganisms in the biocathode. Simultaneous nitrification, denitrification and energy generation using biocathode in MFCs could be realized when involved in nitrogen removal [45].

\section{Cathode Biofouling's Effect on Microbial Fuel Cell Performance}

In specific instances, biofilm formation on the cathode can be employed successfully to accelerate cathode processes deprived of the necessity for external catalysts, hence reducing the need for external catalysts. The conversion of nitrate to nitrogen (denitrification) may be enhanced in the cathode chamber by the usage of electrons from the anode. As a result, the cathodic reduction can be done utilizing nitrate as the terminal electron acceptor (TEA), hence enhancing the efficiency of the MFC. Utilizing a stainlesssteel cathode coated with seawater biofilm in comparison to a control, improved power density was achieved. However, to facilitate such a complex biocatalytic process to a cathode, experimental parameters need to be closely managed, as the enlargement of the biofilm may detrimentally impact the entire chemistry over the days of service and may ultimately decrease the efficiency of the MFC Fig. 8. The overpotential loss which arise during the reduction stage on the cathode have a significant impact on the efficacy of MFC. The development of a biofilm on the catalyst is a critical factor affecting cathode 
kinetics, or processes involving ORR. Two of the most significant disadvantages of cathode biofouling are that it (1) reduces the flow of oxygen to the catalyst substrate, which limits the reduction of oxygen concentration and raises the flow of charge as well as diffusion resistance; and (2) prevents the transfer of protons from the membrane to the sites of reduction. Tab. 3 lists a number of cathode biofouling experiments, each of which illustrates the consequences [156].

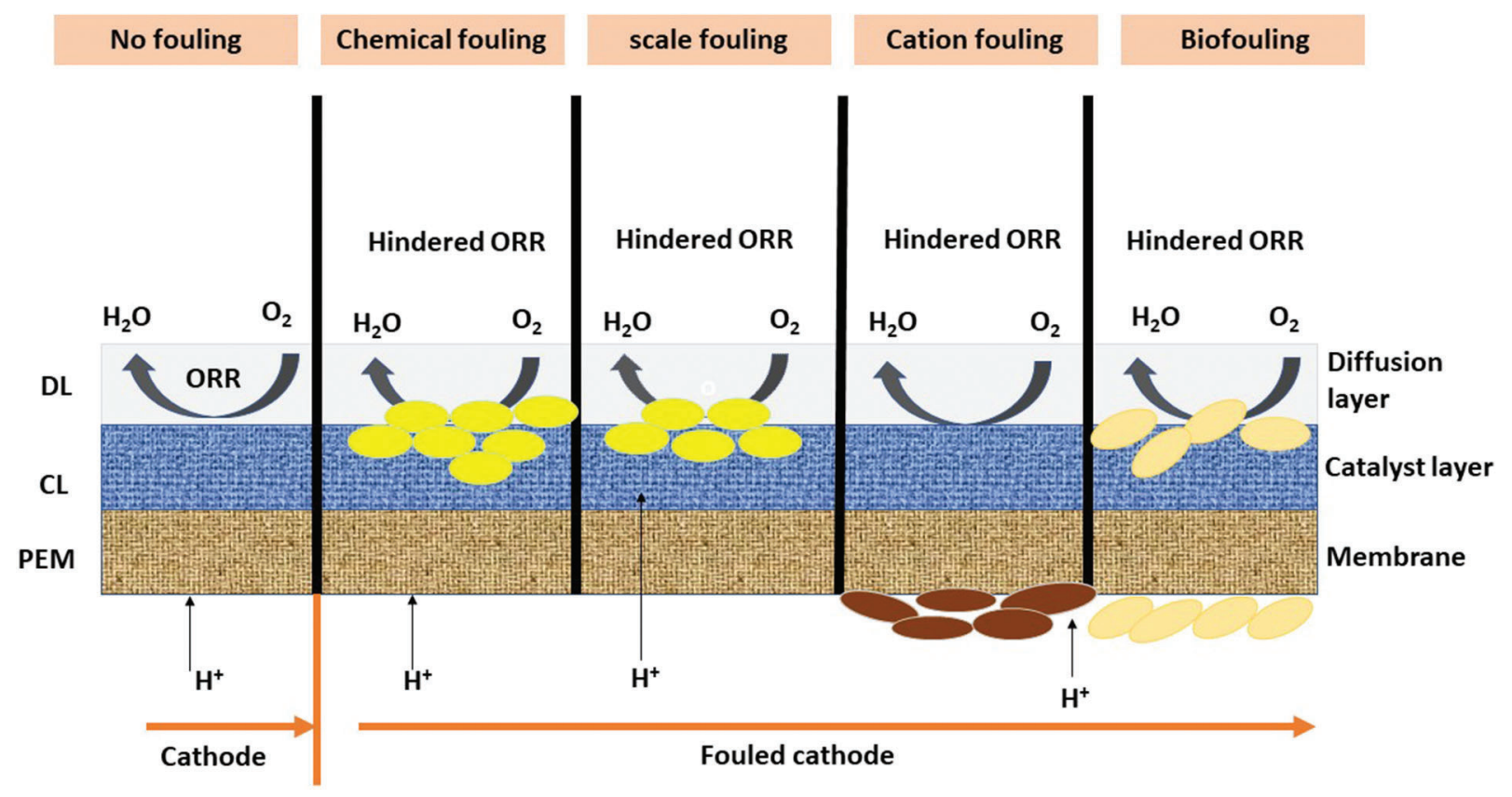

Figure 8: Several types of fouling and its effect on ORR activity

Table 3: Various cathode biofouling studies

\begin{tabular}{|c|c|c|c|c|c|}
\hline Sr. no. & Strategies & Cathode composition & $\mathrm{P}_{\max }$ (under biofouling) & $\mathrm{P}_{\max }($ after treatment $)$ & Reference \\
\hline 1. & $\begin{array}{l}\text { Lysis buffer }\left(60^{\circ} \mathrm{C}\right)- \\
\text { wash -deionized water } \\
\text { Lysis+an extra layer of } \\
\text { catalyst }\end{array}$ & $\begin{array}{l}\text { Graphite- } \\
\text { polyurethane rubber } \\
\text { solution }\end{array}$ & $135 \mu \mathrm{W}$ & $28.6 \mu \mathrm{W}$ & [157] \\
\hline \multirow[t]{3}{*}{2.} & $\begin{array}{l}\text { Scarping salt/biofilm } \\
\text { (from cathode) }\end{array}$ & $\begin{array}{l}\text { Activated carbon air } \\
\text { cathodes wrapped } \\
\text { with Stainless steel } \\
\text { wire mesh }\end{array}$ & $777 \pm 19 \mathrm{~mW} / \mathrm{m}^{2}$ & $834 \pm 41 \mathrm{~mW} / \mathrm{m}^{2}$ & [158] \\
\hline & $\begin{array}{l}\text { Scarping salt/biofilm, } \\
\text { wash- deionized water- } \\
\text { dried-repressed } \\
\text { membrane }\end{array}$ & & $777 \pm 19 \mathrm{~mW} / \mathrm{m}^{2}$ & $\sim 1200 \mathrm{~mW} / \mathrm{m}^{2}$ & [158] \\
\hline & $\begin{array}{l}\text { Scarping salt/biofilm, } \\
\text { soak ( } 0.1 \mathrm{M} \text { HCL) ( } 24 \\
\text { h), wash-deionized }\end{array}$ & & $777 \pm 19 \mathrm{~mW} / \mathrm{m}^{2}$ & $1518 \pm 38 \mathrm{~mW} / \mathrm{m}^{2}$ & [158] \\
\hline
\end{tabular}


JRM, 2022, vol.10, no.3

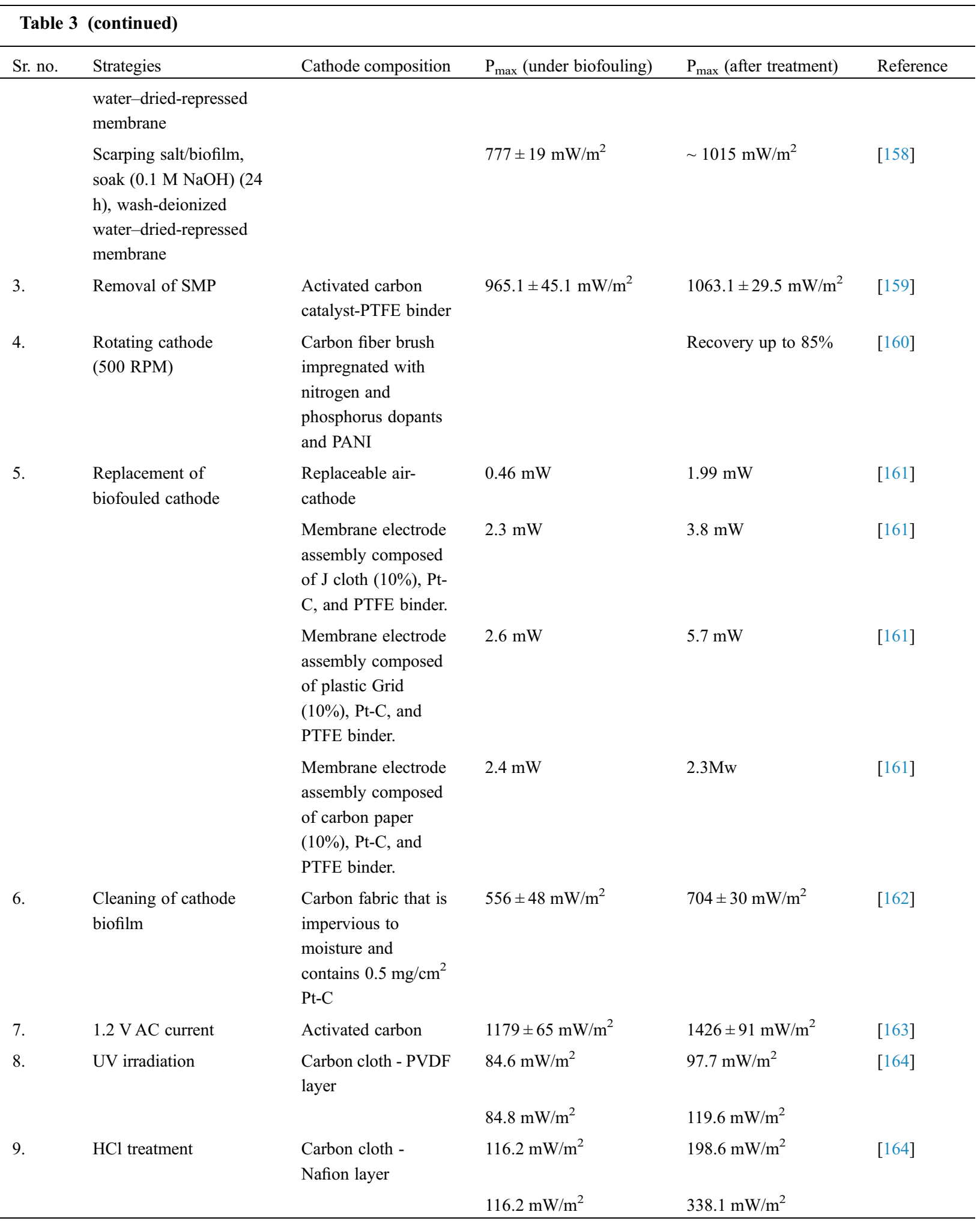




\section{Cost Analysis of Cathode Catalysts}

In developing MFC's industry, the catalyst value is a critical problem. The high cost of platinum makes it impractical for MFC upscaling and its commercialization. The above-mentioned low-cost cathode catalyst for MFCs are investigated and discussed in Tab. 4.

Table 4: Cost estimation of various cathode catalysts

\begin{tabular}{|c|c|c|c|c|}
\hline $\begin{array}{l}\text { Sr. } \\
\text { No. }\end{array}$ & Cathode catalyst & $\begin{array}{l}\text { Cost for } \\
\text { catalyst }\end{array}$ & $\begin{array}{l}\text { Cost for catalyst }+ \\
\text { MFCs }\end{array}$ & Reference \\
\hline 1. & Platinum $(\mathrm{Pt})$ & $\$ 150$ & $\$ 780-1340$ & $\begin{array}{l}\text { Alfa Aesar, Johnson Matthew } \\
\text { Company, United Kingdom. }\end{array}$ \\
\hline 2. & Fe-AAPyr & $\$ 3.20-3.40$ & \$215-296 & $\begin{array}{l}\text { Alfa Aesar, Johnson Matthew } \\
\text { Company, United Kingdom. }\end{array}$ \\
\hline 3. & Fe-Mebendazole & $\$ 3.40-3.60$ & $\$ 262-329$ & $\begin{array}{l}\text { Alfa Aesar, Johnson Matthew } \\
\text { Company, United Kingdom. }\end{array}$ \\
\hline 4. & CoNPc & $\$ 0.0114 / \mathrm{cm}^{2}$ & & {$[165]$} \\
\hline 5. & $\mathrm{MnO}_{2}$ & $\$ 3.84$ & & [166] \\
\hline 6. & MWCNTs $(95 \%,<7 \mathrm{~nm})$ & $\$ 1960$ & & {$[167]$} \\
\hline 7. & GO-MgO & $\$ 2.2 / \mathrm{g}$ & & [98] \\
\hline 8. & $\mathrm{CuZn}$ & $\$ 90.42$ & & {$[168]$} \\
\hline 9. & Activated carbon & $\$ 0.5 / \mathrm{g}$ & & Sigma Aldrich-Merck \\
\hline 10. & $\mathrm{~V}_{2} \mathrm{O}_{5}-\mathrm{NR} / \mathrm{rGO}$ & $\$ 4.8 / \mathrm{g}$ & & [169] \\
\hline 11. & Copper & $\$ 5528 /$ ton & & {$[167]$} \\
\hline 12. & Nickel & $\$ 14,898 /$ ton & & {$[167]$} \\
\hline 13. & $\begin{array}{l}\text { Industrial graphite nanoplatelet } \\
\text { CNTs composite } \\
\text { aqueous paste }\end{array}$ & $<\$ 50 / \mathrm{kg}$ & & [167] \\
\hline
\end{tabular}

\section{Critical Issues in Utilizing Various Nanomaterials as ORR Catalysts}

ORR catalysts must be exceptionally active/stable and cost-effective in order to promote the large-scale deployment of MFCs. At this time, the reduction of valuable metal catalysts is a major challenge for the usage of valuable metals thus, maintaining ORR operation. While valuable metal alloys and core-shell structures show promise in providing more active sites with restricted valuable metal atoms, the correlation between valuable metals and inexpensive supporting alloys or transition metals is not well understood. Another issue for valuable metal catalysts is insufficient stability when metal loading is low [170]. The critical issue is to enhance ORR activity and stability without adding any metal(s), however some researchers have asserted that some "metal-free" catalysts may be formed by highly active trace metal impurities [171,172].

\section{Conclusion}

In the microbial fuel cell economic expansion, ORR has a significant role to play. Pt demonstrates the most enhanced electrochemical performance in comparison to the ORR electrochemical performance of other single metals, but its practical implementations are constrained due to its high price and scarcity. When a secondary metal is introduced to a metal electrocatalyst, the particle size reduces, resulting in an enhanced lattice strain and, thus, electrocatalytic activity. It is been shown that multi-component catalysts 
boost ORR activity, but it is not clear which multi-catalyst exhibits the highest enhanced ORR activity. more research is required to optimize the combination of components on various multi-component catalysts. However, it is quite clear that metal oxide catalyst which is responsible for improved ORR must be blended with conductive carbon like activated carbon, CNT, graphene etc to enhance the conductivity of the cathode and improved power generation. Biocathode had shown promising due to its renewable nature, nevertheless, its slow kinetics for oxygen reduction limits its frequent use for practical implementation. Another limiting factor of the cathode is biofouling and for which, from physical washing to surface alteration, substantial efforts have been made to avoid and minimize biofouling on the cathodes. While some of the suggested mitigation methods could postpone electrode biofouling, such as hydrophilicity regulation of the binder and surface adjustment, a concentrated acid wash can be seen as a quick and inexpensive method of cleaning to completely recover the efficiency of the cathode. In terms of cathodic biofouling, intermittent treatment of cathode for a short period, with lysis buffer, demineralized water, or nitric acid. Physical washing and re-manufacturing of biofouling contaminated cathode layer was also implemented, but there were still losses in the energy recovery. The use of cathode nanomaterial catalysts based on $\mathrm{Cu}$ briefly demonstrated encouraging impact in improving biofouling in MFCs. More research is required for antifouling ORR based bifunctional catalysts for long term use of MFC. Finally, it can be inferred that, concerning their considerable importance, the investigation of microbial cathodes for ORR catalysis has so far been moderate. Combined methods, including electrochemistry, chemistry, microbiology, genetics, ecology, material science and engineering, need to be thoroughly explored to explore the various pioneering technologies mentioned and, ideally, open up new avenue's dependent on expertise.

Funding Statement: The authors received no specific funding for this study.

Conflicts of Interest: The authors declare that they have no conflicts of interest to report regarding the present study.

\section{References}

1. Savla, N., Shinde, A., Sonawane, K., Mekuto, L., Chowdhary, P. et al. (2020). 17-microbial hydrogen production: Fundamentals to application. In: howdhary, P., Raj, A., Verma, D., Akhter, Y. (eds.), Microorganisms for sustainable environment and health, pp. 343-365. Elsevier, Amsterdam, DOI 10.1016/B978-0-12-8190012.00017-6.

2. Kumbhar, P., Savla, N., Banerjee, S., Mathuriya, A. S., Sarkar A. et al. (2021). Microbial electrochemical heavy metal removal: fundamental to the recent development. In: Shah, M. P., Sarkar, A., Mandal, S. (eds.), Wastewater treatment, pp. 521-542. Elsevier, Amsterdam. DOI 10.1016/B978-0-12-821881-5.00026-X.

3. Savla, N., Pandit, S., Khanna, N., Mathuriya, A. S, Jung, S. P. (2020). Microbially powered electrochemical systems coupled with membrane-based technology for sustainable desalination and efficient wastewater treatment. Journal of Korean Society of Environmental Engineers, 42, 360-380. DOI 10.2020/42.7.360.

4. Puig, S., Serra, M., Coma, M., Balaguer, M. D., Colprim, J. (2011). Microbial fuel cell application in landfill leachate treatment. Journal of Hazardous Materials, 185, 763-767. DOI 10.1016/j.jhazmat.2010.09.086.

5. He, Y. R., Xiao, X., Li, W. W., Sheng, G. P., Yan, F. F. et al. (2012). Enhanced electricity production from microbial fuel cells with plasma-modified carbon paper anode. Physical Chemistry Chemical Physics, 14, 9966. DOI $10.1039 / \mathrm{c} 2 \mathrm{cp} 40873 \mathrm{~b}$.

6. Richter, H., McCarthy, K., Nevin, K. P., Johnson, J. P., Rotello, V. M. et al. (2008). Electricity generation by geobacter sulfurreducens attached to gold electrodes. Langmuir, 24, 4376-4379. DOI 10.1021/la703469y.

7. Salar-García, M. J., Ortiz-Martínez, V. M., Baicha, Z., de los Rios, A. P., Hernandez-Fernandez, F. J. (2016). Scaled-up continuous up-flow microbial fuel cell based on novel embedded ionic liquid-type membranecathode assembly. Energy, 101, 113-120. DOI 10.1016/j.energy.2016.01.078. 
8. Savla, N., Anand, R., Pandit, S., Prasad, R. (2020). Utilization of nanomaterials as anode modifiers for improving microbial fuel cells performance. Journal of Renewable Materials, 8, 1581-1605. DOI 10.32604/ jrm.2020.011803.

9. Pandit, S., Savla, N., Jung, S. P. (2020). 16-recent advancements in scaling up microbial fuel cells. In: Abbassi, R, Yadav, A. K., Khan, F., Garaniya, V. (eds.), Integrated microbial fuel cells for wastewater treatment, pp. 349-368. Butterworth-Heinemann, Oxford, U.K. DOI 10.1016/B978-0-12-817493-7.00016-3.

10. Das, S., Dutta, K., Rana, D. (2018). Polymer electrolyte membranes for microbial fuel cells: A review. Polymer Reviews, 58, 610-629. DOI 10.1080/15583724.2017.1418377.

11. Asensio, Y., Fernandez-Marchante, C. M., Lobato, J., Canizares, P., Rodrigo, M. A. (2018). Influence of the ionexchange membrane on the performance of double-compartment microbial fuel cells. Journal of Electroanalytical Chemistry, 808, 427-432. DOI 10.1016/j.jelechem.2017.06.018.

12. Li, X., Liu, G., Sun, S., Ma, F., Zhou, S. et al. (2018). Power generation in dual chamber microbial fuel cells using dynamic membranes as separators. Energy Conversion and Management, 165, 488-494. DOI 10.1016/j. enconman.2018.03.074.

13. Wei, J., Liang, P., Huang, X. (2011). Recent progress in electrodes for microbial fuel cells. Bioresource Technology, 102, 9335-9344. DOI 10.1016/j.biortech.2011.07.019.

14. Sonawane, J. M., Yadav, A., Ghosh, P. C., Adeloju, S. B. (2017). Recent advances in the development and utilization of modern anode materials for high performance microbial fuel cells. Biosensors and Bioelectronics, 90, 558-576. DOI 10.1016/j.bios.2016.10.014.

15. Hirose, A., Kasai, T., Koga, R., Suzuki, Y., Kouzuma, A. et al. (2019). Understanding and engineering electrochemically active bacteria for sustainable biotechnology. Bioresources and Bioprocessing, 6, 1-15. DOI 10.1186/s40643-019-0245-9.

16. Sonawane, J. M., Patil, S. A., Ghosh, P. C., Adeloju, S. B. (2018). Low-cost stainless-steel wool anodes modified with polyaniline and polypyrrole for high-performance microbial fuel cells. Journal of Power Sources, 379, $103-$ 114. DOI 10.1016/j.jpowsour.2018.01.001.

17. Yasri, N., Roberts, E. P. L., Gunasekaran, S. (2019). The electrochemical perspective of bioelectrocatalytic activities in microbial electrolysis and microbial fuel cells. Energy Reports, 5, 1116-1136. DOI 10.1016/j. egyr.2019.08.007.

18. Cui, H. F., Du, L., Guo, P. B., Zhu, B., Luong, J. H. T. (2015). Controlled modification of carbon nanotubes and polyaniline on macroporous graphite felt for high-performance microbial fuel cell anode. Journal of Power Sources, 283, 46-53. DOI 10.1016/j.jpowsour.2015.02.088.

19. Guo, X., Zhan, Y., Chen, C., Cai, B., Wang, Y. et al. (2016). Influence of packing material characteristics on the performance of microbial fuel cells using petroleum refinery wastewater as fuel. Renewable Energy, 87, 437-444. DOI 10.1016/j.renene.2015.10.041.

20. Tang, J., Yuan, Y., Liu, T., Zhou, S. (2015). High-capacity carbon-coated titanium dioxide core-shell nanoparticles modified three dimensional anodes for improved energy output in microbial fuel cells. Journal of Power Sources, 274, 170-176. DOI 10.1016/j.jpowsour.2014.10.035.

21. Ci, S., Wen, Z., Chen, J., He, Z. (2012). Decorating anode with bamboo-like nitrogen-doped carbon nanotubes for microbial fuel cells. Electrochemistry Communications, 14, 71-74. DOI 10.1016/j.elecom.2011.11.006.

22. Zhao, H., Li, L., Yang, J., Zhang, Y. (2008). Nanostructured polypyrrole/carbon composite as Pt catalyst support for fuel cell applications. Journal of Power Sources, 184, 375-380. DOI 10.1016/j.jpowsour.2008.03.024.

23. Wen, Z., Ci, S., Mao, S., Cui, S., Lu, G. et al. (2013). Tio 2 nanoparticles-decorated carbon nanotubes for significantly improved bioelectricity generation in microbial fuel cells. Journal of Power Sources, 234, 100 106. DOI 10.1016/j.jpowsour.2013.01.146.

24. Wang, Y. (2014). Microwave absorbing materials based on polyaniline composites: A review. International Journal of Materials Research, 105, 3-12. DOI 10.3139/146.110996.

25. Zhu, X., Logan, B. E. (2014). Copper anode corrosion affects power generation in microbial fuel cells. Journal of Chemical Technology and Biotechnology, 89, 471-474. DOI 10.1002/jctb.4156. 
26. Xia, X., Li, M., Liu, T., Liang, P., Huang, X. (2018). Facile synthesis of cobalt oxide as electrocatalyst for the oxygen reduction reaction in microbial fuel cells. Chemical Engineering Journal, 342, 395-400. DOI 10.1016/ j.cej.2018.02.092.

27. Ren, P., Ci, S., Ding, Y., Wen, Z. (2019). Molten-salt-mediated synthesis of porous Fe-containing N-doped carbon as efficient cathode catalysts for microbial fuel cells. Applied Surface Science, 481, 1206-1212. DOI 10.1016/j. apsusc.2019.03.279.

28. Chen, S., Patil, S. A., Schröder, U. (2018). A high-performance rotating graphite fiber brush air-cathode for microbial fuel cells. Applied Energy, 211, 1089-1094. DOI 10.1016/j.apenergy.2017.12.013.

29. Tugtas, A. E., Cavdar, P., Calli, B. (2011). Continuous flow membrane-less air cathode microbial fuel cell with spunbonded olefin diffusion layer. Bioresource Technology, 102, 10425-10430. DOI 10.1016/j. biortech.2011.08.082.

30. Tofighi, A., Rahimnejad, M., Ghorbani, M. (2019). Ternary nanotube $\alpha-\mathrm{MnO}_{2} / \mathrm{GO} / \mathrm{AC}$ as an excellent alternative composite modifier for cathode electrode of microbial fuel cell. Journal of Thermal Analysis and Calorimetry, 135, 1667-1675. DOI 10.1007/s10973-018-7198-7.

31. Khilari, S., Pandit, S., Ghangrekar, M. M., Das, D., Pradhan, D. (2013). Graphene supported $\alpha-\mathrm{mnO}_{2}$ nanotubes as a cathode catalyst for improved power generation and wastewater treatment in single-chambered microbial fuel cells. RSC Advances, 3, 7902. DOI 10.1039/c3ra22569k.

32. Kumar, R., Singh, L., Zularisam, A. W. (2017). Enhanced oxygen reduction reaction in air-cathode microbial fuel cells using flower-like $\mathrm{Co}_{3} \mathrm{O}_{4}$ as an efficient cathode catalyst. International Journal of Hydrogen Energy, 42, 19287-19295. DOI 10.1016/j.ijhydene.2017.06.065.

33. Ahmed, J., Yuan, Y., Zhou, L., Kim, S. (2012). Carbon supported cobalt oxide nanoparticles-iron phthalocyanine as alternative cathode catalyst for oxygen reduction in microbial fuel cells. Journal of Power Sources, 208, 170 175. DOI 10.1016/j.jpowsour.2012.02.005.

34. Chandrasekhar, K. (2019). Effective and nonprecious cathode catalysts for oxygen reduction reaction in microbial fuel cells. In: Mohan, S. V., Varjani, S., Pandey, A. (eds.), Microbial electrochemical technology, pp. 485-501. Elsevier, Amsterdam, DOI 10.1016/B978-0-444-64052-9.00019-4.

35. Clauwaert, P., Aelterman, P., Pham, T. H., Schamphelaire, D. L., Carballa, M. et al. (2008). Minimizing losses in bio-electrochemical systems: The road to applications. Applied Microbiology Biotechnology, 79, 901-913. DOI 10.1007/s00253-008-1522-2.

36. Jung, S. P., Pandit, S. (2019). Important factors influencing microbial fuel cell performance. In: Mohan, S. V., Varjani, S., Pandey, A. (eds.), Microbial electrochemical technology, pp. 377-406. Elsevier, Amsterdam, DOI 10.1016/B978-0-444-64052-9.00015-7.

37. Khotseng, L. (2018). Oxygen Reduction Reaction. In: Ray A., Mukhopadhyay I., Pati R. K., Electrocatalysts for fuel cells and hydrogen evolution-theory to design. DOI 10.5772/intechopen.79098.

38. Wroblowa, H. S., Yen-Chi, P., Razumney, G. (1976). Electroreduction of oxygen: A new mechanistic criterion. Journal of Electroanalytical Chemistry and Interfacial Electrochemistry, 69, 195-201. DOI 10.1016/S00220728(76)80250-1.

39. Gewirth, A. A., Varnell, J. A., DiAscro, A. M. (2018). Nonprecious metal catalysts for oxygen reduction in heterogeneous aqueous systems. Chemical Reviews, 118, 2313-2339. DOI 10.1021/acs.chemrev.7b00335.

40. Nørskov, J. K., Rossmeisl, J., Logadottir, A., Lindqvist, L., kitchin, J. R. et al. (2004). Origin of the overpotential for oxygen reduction at a fuel-cell cathode. The Journal of Physical Chemistry B, 108, 17886-17892. DOI $10.1021 / \mathrm{jp} 047349 \mathrm{j}$.

41. Shao, M., Chang, Q., Dodelet, J. P., Chenitz, R. (2016). Recent advances in electrocatalysts for oxygen reduction reaction. Chemical Reviews, 116, 3594-3657. DOI 10.1021/acs.chemrev.5b00462.

42. Stephens, I. E. L., Bondarenko, A. S., Grønbjerg, U., Rossmeisl, J., Chorkendorff, I. B. (2012). Understanding the electrocatalysis of oxygen reduction on platinum and its alloys. Energy \& Environmental Science, 5, 6744-6762. DOI 10.1039/c2ee03590a.

43. Song, C., Zhang, J. (2008). Electrocatalytic oxygen reduction reaction. In: Zhang, J. (ed.), PEM fuel cell electrocatalysts and catalyst layers: fundamentals and applications, pp. 89-134. Springer London, London. 
44. Savla, N., Khilari, S., Pandit, S., Jung, S. P. (2020). Effective cathode catalysts for oxygen reduction reactions in microbial fuel cell. In: Kumar, P., Kuppam, C. (eds.), Bioelectrochemical systems, vol. 1, pp. 189-210. Springer, Singapore, DOI 10.1007/978-981-15-6872-5_9.

45. Khilari, S., Pradhan, D. (2018). Role of cathode catalyst in microbial fuel cell. In: Das, D. (ed.), Microbial fuel cell. pp. 141-163. Springer International Publishing, Cham, DOI 10.1007/978-3-319-66793-5_8.

46. Anderson, A. B., Roques, J., Mukerjee, S., Murthi, V. S., Markovic, N. M. et al. (2005). Activation energies for oxygen reduction on platinum alloys: Theory and experiment. The Journal of Physical Chemistry B, 109, 1198 1203. DOI 10.1021/jp047468z.

47. Shih, Y. H., Sagar, G. V., Lin, S. D. (2008). Effect of electrode Pt loading on the oxygen reduction reaction evaluated by rotating disk electrode and Its implication on the reaction kinetics. The Journal of Physical Chemistry C, 112, 123-130. DOI 10.1021/jp071807h.

48. Zhou, R., Zheng, Y., Jaroniec, M., Qiao, S. Z. (2016). Determination of the electron transfer number for the oxygen reduction reaction: From theory to experiment. ACS Catalysis, 6, 4720-4728. DOI 10.1021/acscatal.6b01581.

49. Khilari, S., Pandit, S., Das, D., Pradhan, D. (2014). Manganese cobaltite/polypyrrole nanocomposite-based aircathode for sustainable power generation in the single-chambered microbial fuel cells. Biosensors and Bioelectronics, 54, 534-540. DOI 10.1016/j.bios.2013.11.044.

50. Tang, Z., Wu, W., Wang, K. (2018). Oxygen reduction reaction catalyzed by noble metal clusters. Catalysts, 8, 65. DOI 10.3390/catal8020065.

51. Liu, J., Yu, M., Wang, X., Wu, J., Wang, C. et al. (2017). Investigation of high oxygen reduction reaction catalytic performance on Mn-based mullite $\mathrm{SmMn}_{2} \mathrm{O}_{5}$. Journal of Materials Chemistry A, 5, 20922-20931. DOI 10.1039/ C7TA02905E.

52. Jiang, Z. J., Jiang, Z. (2014). Reduction of the oxygen reduction reaction overpotential of nitrogen-doped graphene by designing it to a microspherical hollow shape. Journal of Materials Chemistry A, 2, 14071-14081. DOI 10.1039/C4TA01706D.

53. Wang, J. X., Uribe, F. A., Springer, T. E., Zhang, J., Adzic, R. R. (2008). Intrinsic kinetic equation for oxygen reduction reaction in acidic media: The double tafel slope and fuel cell applications. Faraday Discuss, 140, 347-362. DOI 10.1039/B802218F.

54. Santoro, C., Serov, A., Narvaez Villarrubia, C. W., Stariha, B. et al. (2015). Double-chamber microbial fuel cell with a non-platinum-group metal Fe-N-C cathode catalyst. ChemSusChem, 8, 828-834. DOI 10.1002/cssc.201402570.

55. Kodali, M., Santoro, C., Serov, A., Kabir, S., Artyushkova, K. et al. (2017). Air breathing cathodes for microbial fuel cell using Mn-, Fe-, Co- and Ni-containing platinum group metal-free catalysts. Electrochimica Acta, 231, 115-124. DOI 10.1016/j.electacta.2017.02.033.

56. Ge, B., Li, K., Fu, Z., Pu, L., Zhang, X. et al. (2016). The performance of nano urchin-like $\mathrm{NiCo}_{2} \mathrm{O}_{4}$ modified activated carbon as air cathode for microbial fuel cell. Journal of Power Sources, 303, 325-332. DOI 10.1016/ j.jpowsour.2015.11.003.

57. Kodali, M., Santoro, C., Herrera, S., Serov, A., Atanassov, P. (2017). Bimetallic platinum group metal-free catalysts for high power generating microbial fuel cells. Journal of Power Sources, 366, 18-26. DOI 10.1016/j. jpowsour.2017.08.110.

58. Kodali, M., Herrera, S., Kabir, S., Santoro, C., Leropoulos, I. et al. (2018). Enhancement of microbial fuel cell performance by introducing a nano-composite cathode catalyst. Electrochimica Acta, 265, 56-64. DOI 10.1016/j.electacta.2018.01.118.

59. Gajda, I., Greenman, J., Santoro, C., Serov, A., Melhuish, C. et al. (2018). Improved power and long term performance of microbial fuel cell with Fe-N-C catalyst in air-breathing cathode. Energy, 144, 1073-1079. DOI 10.1016/j.energy.2017.11.135.

60. Santoro, C., Kodali, M., Herrera, S., Serov, A., Leropoulos, I. et al. (2018). Power generation in microbial fuel cells using platinum group metal-free cathode catalyst: Effect of the catalyst loading on performance and costs. Journal of Power Sources, 378, 169-175. DOI 10.1016/j.jpowsour.2017.12.017. 
61. Wang, L., Liang, P., Zhang, J., Huang, X. (2011). Activity and stability of pyrolyzed iron ethylenediaminetetraacetic acid as cathode catalyst in microbial fuel cells. Bioresource Technology, 102, 5093-5097. DOI 10.1016/j. biortech.2011.01.025.

62. Liu, J., Liu, Y., Li, P., Wang, L., Zhang, H. et al. (2018). Fe-n-doped porous carbon from petroleum asphalt for highly efficient oxygen reduction reaction. Carbon, 126, 1-8. DOI 10.1016/j.carbon.2017.10.004.

63. Santoro, C., Serov, A., Stariha, L., Kodali, M., Gordon, J. et al. (2016). Iron based catalysts from novel low-cost organic precursors for enhanced oxygen reduction reaction in neutral media microbial fuel cells. Energy \& Environmental Science, 9, 2346-2353. DOI 10.1039/C6EE01145D.

64. Santoro, C., Gokhale, R., Mecheri, B., D'Epifanio, A., Licoccia, S. et al. (2017). Design of iron(II) phthalocyaninederived oxygen reduction electrocatalysts for high-power-density microbial fuel cells. ChemSusChem, 10, 32433251. DOI 10.1002/cssc.201700851.

65. Kim, J. R., Kim, J. Y., Han, S. B., Park, K. W., Saratale, G. D. et al. (2011). Application of Co-naphthalocyanine (CoNPc) as alternative cathode catalyst and support structure for microbial fuel cells. Bioresource Technology, 102, 342-347. DOI 10.1016/j.biortech.2010.07.005.

66. Song, T., Wang, D., Wang, H., Li, X. (2015). Sciencedirect cobalt oxide/nanocarbon hybrid materials as alternative cathode catalyst for oxygen reduction in microbial fuel cell. International Journal of Hydrogen Energy, 40, 38683874. DOI 10.1016/j.ijhydene.2015.01.119.

67. Cao, C., Wei, L., Wang, G., Shen, J. (2017). In-situ growing $\mathrm{NiCo}_{2} \mathrm{O}_{4}$ nanoplatelets on carbon cloth as binder-free catalyst air-cathode for high-performance microbial fuel cells. Electrochimica Acta, 231, 609-616. DOI 10.1016/j. electacta.2017.02.117.

68. Liu, B., Brùckner, C., Lei, Y., Cheng, Y., Santoro, C. et al. (2014). Cobalt porphyrin-based material as methanol tolerant cathode in single chamber microbial fuel cells (SCMFCs). Journal of Power Sources, 257, 246-253. DOI 10.1016/j.jpowsour.2014.01.117.

69. Noori, M. T., Verma, N. (2019). Cobalt-iron phthalocyanine supported on carbide-derived carbon as an excellent oxygen reduction reaction catalyst for microbial fuel cells. Electrochimica Acta, 298, 70-79. DOI 10.1016/j. electacta.2018.12.056.

70. Rozenfeld, S., Schechter, M., Teller, H., Cahan, R., Schechter, A. (2017). Novel ruCoSe as non-platinum catalysts for oxygen reduction reaction in microbial fuel cells. Journal of Power Sources, 362, 140-146. DOI 10.1016/j. jpowsour.2017.07.022.

71. Hirooka, K., Ichihashi, O., Takeguchi, T. (2018). Sodium cobalt oxide as a non-platinum cathode catalyst for microbial fuel cells. Sustainable Environment Research, 28, 322-325. DOI 10.1016/j.serj.2018.07.002.

72. Xin, S., Shen, J., Liu, G., Chen, Q., Xiao, Z. et al. (2020). Electricity generation and microbial community of single-chamber microbial fuel cells in response to $\mathrm{Cu}_{2} \mathrm{O}$ nanoparticles/reduced graphene oxide as cathode catalyst. Chemical Engineering Journal, 380, 122446. DOI 10.1016/j.cej.2019.122446.

73. Li, H., Ma, H., Liu, T., Ni, J., Wang, Q. (2019). An excellent alternative composite modifier for cathode catalysts prepared from bacterial cellulose doped with $\mathrm{Cu}$ and $\mathrm{P}$ and its utilization in microbial fuel cell. Bioresource Technology, 289, 121661. DOI 10.1016/j.biortech.2019.121661.

74. Sonawane, J. M., Pant, D., Ghosh, P. C., Adeloju, S. B. (2019). Fabrication of a carbon paper/Polyaniline-copper hybrid and Its utilization as an Air cathode for microbial fuel cells. ACS Applied Energy Materials, 2, 1891-1902. DOI 10.1021/acsaem.8b02017.

75. Włodarczyk, B., Włodarczyk, P. P. (2017). Microbial fuel cell with $\mathrm{Cu}-\mathrm{B}$ cathode powering with wastewater from yeast production. Journal of Ecological Engineering, 18, 224-230. DOI 10.12911/22998993/74287.

76. Tan, L., Liu, Z. Q., Li, N., Zhang, J. Y., Zhang, L. et al. (2016). Cuse decorated carbon nanotubes as a high performance cathode catalyst for microbial fuel cells. Electrochimica Acta, 213, 283-290. DOI 10.1016/j. electacta.2016.07.099.

77. Yang, T., Li, K., Liu, Z., Pu, L., Zhang, X. (2017). One-step synthesis of hydrangea-like $\mathrm{Cu}_{2} \mathrm{O}$ @ N-doped activated carbon as Air cathode catalyst in microbial fuel cell. Journal of the Electrochemical Society, 164, F270-F275. DOI 10.1149/2.0401704jes. 
78. Sun, Y., Duan, Y., Hao, L., Xing, Z., Dai, Y. et al. (2016). Cornstalk-derived nitrogen-doped partly graphitized carbon as efficient metal-free catalyst for oxygen reduction reaction in microbial fuel cells. ACS Applied Materials and Interfaces, 8, 25923-25932. DOI 10.1021/acsami.6b06895.

79. Tang, H., Zeng, Y., Zeng, Y., Wang, R., Cai, S. et al. (2017). Iron-embedded nitrogen doped carbon frameworks as robust catalyst for oxygen reduction reaction in microbial fuel cells. Applied Catalysis B: Environmental, 202, 550-556. DOI 10.1016/j.apcatb.2016.09.062.

80. Dai, Y., Chan, Y., Jiang, B., Wang, L., Zou, J. et al. (2016). Bifunctional Ag/Fe/N/C catalysts for enhancing oxygen reduction via cathodic biofilm inhibition in microbial fuel cells. ACS Applied Materials and Interfaces, 8, 6992-7002. DOI 10.1021/acsami.5b11561.

81. Cao, C., Wei, L., Su, M., Wang, G., Shen, J. (2016). Low-cost adsorbent derived and in situ nitrogen/iron codoped carbon as efficient oxygen reduction catalyst in microbial fuel cells. Bioresource Technology, 214, 348354. DOI 10.1016/j.biortech.2016.04.111.

82. Wang, D., Ma, Z., Meng, X. Song, H. (2018). Preparation and characterization of Fe-doped PAA as air-cathode electrocatalyst in microbial fuel cells. Catalysis Communications, 105, 56-58. DOI 10.1016/j.catcom.2017.11.013.

83. Hao, L., Yu, J., Xu, X., Yang, L., Xing, Z. et al. (2017). Nitrogen-doped $\mathrm{MoS}_{2} /$ carbon as highly oxygenpermeable and stable catalysts for oxygen reduction reaction in microbial fuel cells. Journal of Power Sources, 339, 68-79. DOI 10.1016/j.jpowsour.2016.11.041.

84. Palaniselvam, T., Kashyap, V., Bhange, S. N., Baek, J. B., Kurungot, S. (2016). Nanoporous graphene enriched with $\mathrm{Fe} / \mathrm{Co}-\mathrm{N}$ active sites as a promising oxygen reduction electrocatalyst for anion exchange membrane fuel cells. Advanced Functional Materials, 26, 2150-2162. DOI 10.1002/adfm.201504765.

85. Lu, G., Zhu, Y., Lu, L., Xu, K., Wang, H. et al. (2016). Iron-rich nanoparticle encapsulated, nitrogen doped porous carbon materials as efficient cathode electrocatalyst for microbial fuel cells. Journal of Power Sources, 315, 302 307. DOI 10.1016/j.jpowsour.2016.03.028.

86. Tian, X., Zhou, M., Li, M., Tan, C., Liang, L. et al. (2018). Nitrogen-doped activated carbon as metal-free oxygen reduction catalyst for cost-effective rolling-pressed air-cathode in microbial fuel cells. Fuel, 223, 422-430. DOI 10.1016/j.fuel.2017.11.143.

87. Zhong, K., Li, M., Yang, Y., Zhang, H., Zhang, B. et al. (2019). Nitrogen-doped biochar derived from watermelon rind as oxygen reduction catalyst in air cathode microbial fuel cells. Applied Energy, 242, 516-525. DOI 10.1016/ j.apenergy.2019.03.050.

88. Meng, K., Liu, Q., Huang, Y., Wang, Y. (2015). Facile synthesis of nitrogen and fluorine co-doped carbon materials as efficient electrocatalysts for oxygen reduction reactions in air-cathode microbial fuel cells. Journal of Materials Chemistry A, 3, 6873-6877. DOI 10.1039/C4TA06500J.

89. Lu, M., Kharkwal, S., Ng, H. Y., Li, S. F. Y., (2011). Carbon nanotube supported $\mathrm{MnO}_{2}$ catalyst for oxygen reduction reaction and their applications in microbial fuel cells. Biosensors and Bioelectronics, 26, 47284732. DOI 10.1016/j.bios.2011.05.036.

90. Mahmoud, M., Gad-Allah, T. A., El-Khatib, K. M., El-Gohary, F. (2011). Power generation using spinel manganese-cobalt oxide as a cathode catalyst for microbial fuel cell applications. Bioresource Technology, 102, 10459-10464. DOI 10.1016/j.biortech.2011.08.123.

91. Singh, S., Bairagi, P. K., Verma, N. (2018). Candle soot-derived carbon nanoparticles: An inexpensive and efficient electrode for microbial fuel cells. Electrochimica Acta, DOI 10.1016/j.electacta.2018.01.110.

92. Bhowmick, G. D., Das, S., Verma, H. K., Neethu, B., Ghangrekar, M. M. (2019). Improved performance of microbial fuel cell by using conductive ink printed cathode containing $\mathrm{Co}_{3} \mathrm{O}_{4}$ or $\mathrm{Fe}_{3} \mathrm{O}_{4}$. Electrochimica Acta, 310, 173-183. DOI 10.1016/j.electacta.2019.04.127.

93. Kumar, R., Singh, L., Wahid, Z. A., Mahapatra, D. M., Liu, H. (2018). Novel mesoporous $\mathrm{MnCo}_{2} \mathrm{O}_{4}$ nanorods as oxygen reduction catalyst at neutral $\mathrm{pH}$ in microbial fuel cells. Bioresource Technology, 254, 1-6. DOI 10.1016/j. biortech.2018.01.053.

94. Feng, L., Chen, Y., Chen, L. (2011). Easy-to-operate and low-temperature synthesis of gram-scale nitrogen-doped graphene and its application as cathode catalyst in microbial fuel cells. ACS Nano, 5, 9611-9618. DOI 10.1021/ nn202906f. 
95. Gnana kumar, G., Awan, Z., Suk Nahm, K., Stanley Xavier, J. (2014). Nanotubular $\mathrm{MnO}_{2}$ /graphene oxide composites for the application of open air-breathing cathode microbial fuel cells. Biosensors and Bioelectronics, 53, 528-534. DOI 10.1016/j.bios.2013.10.012.

96. Li, S., Hu, Y., Xu, Q., Sun, J., Hou, B. et al. (2012). Iron- and nitrogen-functionalized graphene as a non-precious metal catalyst for enhanced oxygen reduction in an air-cathode microbial fuel cell. Journal of Power Sources, 213, 265-269. DOI 10.1016/j.jpowsour.2012.04.002.

97. Wen, Q., Wang, S., Yan, J., Cong, L., Chen, Y. et al. (2014). Porous nitrogen-doped carbon nanosheet on graphene as metal-free catalyst for oxygen reduction reaction in air-cathode microbial fuel cells. Bioelectrochemistry, 95, 23-28. DOI 10.1016/j.bioelechem.2013.10.007.

98. Li, M., Zhou, S., Xu, M. (2017). Graphene oxide supported magnesium oxide as an efficient cathode catalyst for power generation and wastewater treatment in single chamber microbial fuel cells. Chemical Engineering Journal, 328, 106-116. DOI 10.1016/j.cej.2017.07.031.

99. Cao, C., Wei, L., Zhai, Q., Ci, J., Li, W. et al. (2017). Gas-flow tailoring fabrication of graphene-like Co-Nx-c nanosheet supported Sub-10 nm PtCo nanoalloys as synergistic catalyst for air-cathode microbial fuel cells. ACS Applied Materials and Interfaces, 9, 22465-22475. DOI 10.1021/acsami.7b04564.

100. Wang, Q., Zhang, X., Lv, R., Chen, X., Xue, B. et al. (2016). Binder-free nitrogen-doped graphene catalyst aircathodes for microbial fuel cells. Journal of Materials Chemistry A, 4, 12387-12391. DOI 10.1039/ C6TA03642B.

101. Zhu, J., He, G., Tian, Z., Liang, L., Shen, P. K. et al. (2016). Facile synthesis of boron and nitrogen-dual-doped graphene sheets anchored platinum nanoparticles for oxygen reduction reaction. Electrochimica Acta, 194, 276282. DOI 10.1016/j.electacta.2016.01.222.

102. Men, B., Sun, Y., Li, M., Hu, C., Zhang, M. et al. (2016). Hierarchical metal-free nitrogen-doped porous graphene/Carbon composites as an efficient oxygen reduction reaction catalyst. ACS Applied Materials and Interfaces, 8, 1415-1423. DOI 10.1021/acsami.5b10642.

103. Su, Y., Zhu, Y., Yang, X., Shen, J., Lu, J. et al. (2013). A highly efficient catalyst toward oxygen reduction reaction in neutral media for microbial fuel cells. Industrial \& Engineering Chemistry Research, 52, 60766082. DOI 10.1021/ie4003766.

104. Qiao, X., Liao, S., Wang, G., Zheng, R., Song, H. et al. (2016). Simultaneous doping of nitrogen and fluorine into reduced graphene oxide: A highly active metal-free electrocatalyst for oxygen reduction. Carbon, 99, 272-279. DOI 10.1016/j.carbon.2015.12.034.

105. Hu, Z., Zhou, X., Lu, Y., Jv, R., Liu, Y. et al. (2019). $\mathrm{CoMn}_{2} \mathrm{O}_{4}$ doped reduced graphene oxide as an effective cathodic electrocatalyst for ORR in microbial fuel cells. Electrochimica Acta, 296, 214-223. DOI 10.1016/j. electacta.2018.11.004.

106. Lv, C., Liang, B., Zhong, M., Li, K., Qi, Y. Y. (2019). Activated carbon-supported multi-doped graphene as highefficient catalyst to modify air cathode in microbial fuel cells. Electrochimica Acta, 304, 360-369. DOI 10.1016/j. electacta.2019.02.094.

107. Dong, H., Liu, X., Xu, T., Wang, Q., Chen, X. et al. (2018). Hydrogen peroxide generation in microbial fuel cells using graphene-based air-cathodes. Bioresource Technology, 247, 684-689. DOI 10.1016/j.biortech.2017.09.158.

108. Wang, H., Wu, Z., Plaseied, A., Jenkins, P., Simpson, L. et al. (2011). Carbon nanotube modified air-cathodes for electricity production in microbial fuel cells. Journal of Power Sources, 196, 7465-7469. DOI 10.1016/j. jpowsour.2011.05.005.

109. Amade, R., Vila-Costa, M., Hussain, S., Casamayor, E. O., Bertran, E. (2015). Vertically aligned carbon nanotubes coated with manganese dioxide as cathode material for microbial fuel cells. Journal of Materials Science, 50, 1214-1220. DOI 10.1007/s10853-014-8677-2.

110. Zhang, Y., Hu, Y., Li, S., Sun, J., Hou, B. (2011). Manganese dioxide-coated carbon nanotubes as an improved cathodic catalyst for oxygen reduction in a microbial fuel cell. Journal of Power Sources, 196, 9284-9289. DOI 10.1016/j.jpowsour.2011.07.069. 
111. Ghasemi, M., Ismail, M., Kamarudin, S. K., Saeedfar, K., Daud, W. R. W. et al. (2013). Carbon nanotube as an alternative cathode support and catalyst for microbial fuel cells. Applied Energy, 102, 1050-1056. DOI 10.1016/j. apenergy.2012.06.003.

112. Feng, L., Yan, Y., Chen, Y., Wang, L. (2011). Nitrogen-doped carbon nanotubes as efficient and durable metalfree cathodic catalysts for oxygen reduction in microbial fuel cells. Energy \& Environmental Science, 4, 1892. DOI 10.1039/c1ee01153g.

113. Xie, X., Pasta, M., Hu, L., Yang, Y., McDonough, J. et al. (2011). Nano-structured textiles as high-performance aqueous cathodes for microbial fuel cells. Energy \& Environmental Science, 4, 1293. DOI 10.1039/c0ee00793e.

114. Hsu, W. H., Tsai, H. Y., Huang, Y. C. (2017). Characteristics of carbon nanotubes/Graphene coatings on stainless steel meshes used as electrodes for Air-cathode microbial fuel cells. Journal of Nanomaterials, 2017, 1-9. DOI $10.1155 / 2017 / 9875301$.

115. Nguyen, M. T., Mecheri, B., Iannaci, A., D'Epifanio, A., Licoccia, S. (2016). Iron/Polyindole-based electrocatalysts to enhance oxygen reduction in microbial fuel cells. Electrochimica Acta, 190, 388-395. DOI 10.1016/j.electacta.2015.12.105.

116. Hou, Y., Yuan, H., Wen, Z., Cui, S., Guo, X. et al. (2016). Nitrogen-doped graphene/CoNi alloy encased within bamboo-like carbon nanotube hybrids as cathode catalysts in microbial fuel cells. Journal of Power Sources, 307, 561-568. DOI 10.1016/j.jpowsour.2016.01.018.

117. Liu, Z. Q., Cheng, H., Li, N., Ma, T. Y., Su, Y. Z. (2016). $\mathrm{ZnCo}_{2} \mathrm{O}_{4}$ quantum dots anchored on nitrogen-doped carbon nanotubes as reversible oxygen reduction/Evolution electrocatalysts. Advanced Materials, 28, $3777-$ 3784. DOI 10.1002/adma.201506197.

118. Xu, Y., Zhou, S., Li, M. (2019). Enhanced bioelectricity generation and cathodic oxygen reduction of air breathing microbial fuel cells based on MoS2 decorated carbon nanotube. International Journal of Hydrogen Energy, 44, 13875-13884. DOI 10.1016/j.ijhydene.2019.04.040.

119. Yang, W., Lu, J. E., Zhang, Y., Peng, Y., Mercado, R. et al. (2019). Cobalt oxides nanoparticles supported on nitrogen-doped carbon nanotubes as high-efficiency cathode catalysts for microbial fuel cells. Inorganic Chemistry Communications, 105, 69-75. DOI 10.1016/j.inoche.2019.04.036.

120. Zhu, D., Wang, D. B., Song, T., Guo, T., Ouyang, P. et al. (2015). Effect of carbon nanotube modified cathode by electrophoretic deposition method on the performance of sediment microbial fuel cells. Biotechnology Letters, 37:101-107. DOI 10.1007/s10529-014-1671-6.

121. Jiang, Y., Xu, Y., Yang, Q., Chen, Y., Zhu, S. et al. (2014). Power generation using polyaniline/multi-walled carbon nanotubes as an alternative cathode catalyst in microbial fuel cells. International Journal of Energy Research, 38, 1416-1423. DOI 10.1002/er.3155.

122. Ding, C. H., Tang, J. J., Chen, S., Liu, Z. Q., Li, N. (2017). $\mathrm{Co}_{0.85} \mathrm{Se} /$ multi-walled carbon nanotube composite as alternative cathode catalyst for microbial fuel cells. Journal of Nanoscience and Nanotechnology, 17, 1438-1442. DOI 10.1166/jnn.2017.12697.

123. Zhang, F., Pant, D., Logan, B. E. (2011). Long-term performance of activated carbon air cathodes with different diffusion layer porosities in microbial fuel cells. Biosensors and Bioelectronics, 30, 49-55. DOI 10.1016/j. bios.2011.08.025.

124. Zhang, X., Xia, X., Ivanov, I., Huang, X., Logan, B. E. (2014). Enhanced activated carbon cathode performance for microbial fuel cell by blending carbon black. Environmental Science and Technology, 48, 2075-2081. DOI $10.1021 / \mathrm{es} 405029 \mathrm{y}$.

125. Dong, H., Yu, H., Wang, X., Zhou, Q., Feng, J. (2012). A novel structure of scalable air-cathode without nafion and Pt by rolling activated carbon and PTFE as catalyst layer in microbial fuel cells. Water Research, 46, 57775787. DOI 10.1016/j.watres.2012.08.005.

126. Liu, Z., Ge, B., Li, K., Zhang, X., Huang, K. (2016). The excellent performance and mechanism of activated carbon air cathode doped with different type of cobalt for microbial fuel cells. Fuel, 176, 173-180. DOI 10.1016/j.fuel.2016.02.080. 
JRM, 2022, vol.10, no.3

127. Huang, Q., Zhou, P., Yang, H., Zhu, L., Wu, H. (2017). In situ generation of inverse spinel $\mathrm{CoFe}_{2} \mathrm{O}_{4}$ nanoparticles onto nitrogen-doped activated carbon for an effective cathode electrocatalyst of microbial fuel cells. Chemical Engineering Journal, 325, 466-473. DOI 10.1016/j.cej.2017.05.079.

128. Huang, Q., Zhou, P., Yang, H., Zhu, L., Wu, H. (2017). Coo nanosheets in situ grown on nitrogen-doped activated carbon as an effective cathodic electrocatalyst for oxygen reduction reaction in microbial fuel cells. Electrochimica Acta, 232, 339-347. DOI 10.1016/j.electacta.2017.02.163.

129. Tang., X., Ng, H. Y. (2017). Cobalt and nitrogen-doped carbon catalysts for enhanced oxygen reduction and power production in microbial fuel cells. Electrochimica Acta, 247, 193-199. DOI 10.1016/j. electacta.2017.06.120.

130. Xia, W. Y., Tan, L., Li, N., Li, J. C., Lai, S. H. et al. (2017). Nickel cobaltite@nanocarbon hybrid materials as efficient cathode catalyst for oxygen reduction in microbial fuel cells. Journal of Materials Science, 52, 75397545. DOI 10.1007/s10853-017-0986-9.

131. Song, W., Ren, Z., Chen, S. Y., Meng, Y., Biswas, S. et al. (2016). Ni- and Mn-promoted mesoporous $\mathrm{Co}_{3} \mathrm{O}_{4}$ : A stable bifunctional catalyst with surface-structure-dependent activity for oxygen reduction reaction and oxygen evolution reaction. ACS Applied Materials and Interfaces, 8, 20802-20813. DOI 10.1021/acsami.6b06103.

132. Rossi, R., Yang, W., Setti, L., Logan, B. E. (2017). Assessment of a metal-organic framework catalyst in air cathode microbial fuel cells over time with different buffers and solutions. Bioresource Technology, 233, 399405. DOI 10.1016/j.biortech.2017.02.105.

133. Tang, H., Cai, S., Xie, S., Wang, Z., Tong, Y. et al. (2015). Metal-organic-framework-derived dual metal-and nitrogen-doped carbon as efficient and robust oxygen reduction reaction catalysts for microbial fuel cells. Advanced Science, 3, 1500265. DOI 10.1002/advs.201500265.

134. Xue, W., Zhou, Q., Li, F., Ondon, B. S. (2019). Zeolitic imidazolate framework-8 (ZIF-8) as robust catalyst for oxygen reduction reaction in microbial fuel cells. Journal of Power Sources, 423, 9-17. DOI 10.1016/j. jpowsour.2019.03.017.

135. Liu, Y., Zhao, Y., Li, K., Wang, Z., Tian, P. et al. (2018). Activated carbon derived from chitosan as air cathode catalyst for high performance in microbial fuel cells. Journal of Power Sources, 378, 1-9. DOI 10.1016/j. jpowsour.2017.12.019.

136. Ghasemi, M., Shahgaldi, S., Ismail, M., Kim, B. H., Yaakob, Z. et al. (2011). Activated carbon nanofibers as an alternative cathode catalyst to platinum in a two-chamber microbial fuel cell. International Journal of Hydrogen Energy, 36, 13746-13752. DOI 10.1016/j.jijydene.2011.07.118.

137. Yang, W., Li, J., Ye, D., Zhu, X., Liao, Q. (2017). Bamboo charcoal as a cost-effective catalyst for an air-cathode of microbial fuel cells. Electrochimica Acta, 224, 585-592. DOI 10.1016/j.electacta.2016.12.046.

138. Modi, A., Singh, S., Verma, N. (2016). In situ nitrogen-doping of nickel nanoparticle-dispersed carbon nanofiberbased electrodes: Its positive effects on the performance of a microbial fuel cell. Electrochimica Acta, 190, 620627. DOI 10.1016/j.electacta.2015.12.191.

139. Massaglia, G., Margaria, V., Sacco, A., Castellino, M., Chiodoni, A. et al. (2019). N-doped carbon nanofibers as catalyst layer at cathode in single chamber microbial fuel cells. International Journal of Hydrogen Energy, 42, 4442-4449. DOI 10.1016/j.ijhydene.2018.10.008.

140. Cai, T., Huang, Y., Huang, M., Xi, Y., Pang, D. et al. (2019). Enhancing oxygen reduction reaction of supercapacitor microbial fuel cells with electrospun carbon nanofibers composite cathode. Chemical Engineering Journal, 371, 544-553. DOI 10.1016/j.cej.2019.04.025.

141. Ahn, Y., Ivanov, I., Nagaiah, T. C., Bordoloi, A., Logan, B. E. (2014). Mesoporous nitrogen-rich carbon materials as cathode catalysts in microbial fuel cells. Journal of Power Sources, 269, 212-215. DOI 10.1016/j. jpowsour.2014.06.115.

142. Garino, N., Sacco, A., Castellino, M., Muňoz-Tabares, J. A., Chiodoni, A. et al. (2016). Microwave-assisted synthesis of reduced graphene oxide/ $\mathrm{SnO}_{2}$ nanocomposite for oxygen reduction reaction in microbial fuel cells. ACS Applied Materials \& Interfaces, 8, 4633-4643. DOI 10.1021/acsami.5b11198. 
143. Tan, L., Li, N., Chen, S., Liu, Z. Q. (2016). Self-assembly synthesis of CuSe@graphene-carbon nanotubes as efficient and robust oxygen reduction electrocatalysts for microbial fuel cells. journal of materials chemistry. A, 4, 12273-12280. DOI 10.1039/C6TA02891H.

144. Tan, L., Liu, Z. Q., Li, N., Zhang, J. Y., Zhang, L. et al. (2016). Cuse decorated carbon nanotubes as a high performance cathode catalyst for microbial fuel cells. Electrochimica Acta, 213, 283-290. DOI 10.1016/j. electacta.2016.07.099.

145. Thapa, B., S., Seetharaman, S., Chetty, R., Chandra T. S. (2019). Xerogel based catalyst for improved cathode performance in microbial fuel cells. Enzyme and Microbial Technology, 124, 1-8. DOI 10.1016/j. enzmictec.2019.01.007.

146. Saito, T., Roberts, T. H., Long, T. E., Logan, B. E., Hickner, M. A. (2011). Neutral hydrophilic cathode catalyst binders for microbial fuel cells. Energy \& Environmental Science, 4, 928-934. DOI 10.1039/C0EE00229A.

147. Zhou, X., Xu, Y., Mei, X., Du, N., Jv, R. et al. (2018). Polyaniline/ $\beta$ - $\mathrm{MnO}_{2}$ nanocomposites as cathode electrocatalyst for oxygen reduction reaction in microbial fuel cells. Chemosphere, 198, 482-491. DOI 10.1016/j.chemosphere.2018.01.058.

148. Lu, M., Guo, L., Kharkwal, S., Ng, H. Y., Li, S. F. Y. (2013). Manganese-polypyrrole-carbon nanotube, a new oxygen reduction catalyst for air-cathode microbial fuel cells. Journal of Power Sources, 221, 381-386. DOI 10.1016/j.jpowsour.2012.08.034.

149. Zhang, H., Zhang, R., Zhang, G., Yang, F., Gao, F. (2014). Modified graphite electrode by polyaniline/tourmaline improves the performance of bio-cathode microbial fuel cell. International Journal of Hydrogen Energy, 39, 11250-11257. DOI 10.1016/j.jijhydene.2014.05.057.

150. Ahn, Y., Jo, S. Y., Song, Y. C., Lee, W., Chung, J. W. (2017). Application of reticulated vitreous carbons doped with low-cost catalysts as the cathodes in microbial fuel cells. KSCE Journal of Civil Engineering, 21, 623-628. DOI 10.1007/s12205-016-1792-7.

151. Li, R., Dai, Y., Chen, B., Zou, J., Jiang, B. J. et al. (2016). Nitrogen-doped Co/Co $\mathrm{C}_{9} \mathrm{~S}_{8} /$ partly-graphitized carbon as durable catalysts for oxygen reduction in microbial fuel cells. Journal of Power Sources, 307, 1-10. DOI 10.1016/j.jpowsour.2015.12.115.

152. Ansari, S. A., Parveen, N., Han, H., Ansari, O. (2016). Fibrous polyaniline @ manganese oxide nanocomposites as supercapacitor electrode materials and cathode catalysts for improved. Physical Chemistry Chemical Physics, 18, 9053-9060. DOI 10.1039/C6CP00159A.

153. Ghasemi, M., Wan Daud, W. R., Hassan, S. H. A., Jafary, T., Rahlmnejad, M. et al. (2016). Carbon nanotube/ polypyrrole nanocomposite as a novel cathode catalyst and proper alternative for $\mathrm{Pt}$ in microbial fuel cell. International Journal of Hydrogen Energy, 41, 4872-4878. DOI 10.1016/j.ijhydene.2015.09.011.

154. Yuan, H., Deng, L., Chen, Y., Yuan, Y. (2016). $\mathrm{MnO}_{2} /$ Polypyrrole/ $\mathrm{MnO}_{2}$ multi-walled-nanotube-modified anode for high-performance microbial fuel cells. Electrochimica Acta, 196, 280-285. DOI 10.1016/j.electacta.2016.02.183.

155. Liu, Y., Fan, Y. S., Liu, Z. M. (2019). Pyrolysis of iron phthalocyanine on activated carbon as highly efficient nonnoble metal oxygen reduction catalyst in microbial fuel cells. Chemical Engineering Journal, 361, 416-427. DOI 10.1016/j.cej.2018.12.105.

156. Noori, M. D. T., Ghangrekar, M. M., Mukherjee, C. K., Min, B. (2019). Biofouling effects on the performance of microbial fuel cells and recent advances in biotechnological and chemical strategies for mitigation. Biotechnology Advances, 37, 107420. DOI 10.1016/j.biotechadv.2019.107420.

157. Ghadge, A. N., Ghangrekar, M. M. (2015). Performance of low cost scalable air-cathode microbial fuel cell made from clayware separator using multiple electrodes. Bioresource Technology, 182, 373-377. DOI 10.1016/j. biortech.2015.01.115.

158. Zhang, E., Wang, F., Yu, Q., Scott, K., Wang, X. et al. (2017). Durability and regeneration of activated carbon aircathodes in long-term operated microbial fuel cells. Journal of Power Sources, 360, 21-27. DOI 10.1016/j. jpowsour.2017.05.119.

159. Liu, W., Cheng, S., Yin, L., Sun, Y., Yu, L. (2018). Influence of soluble microbial products on the long-term stability of air cathodes in microbial fuel cells. Electrochimica Acta, 261, 557-564. DOI 10.1016/j. electacta.2017.12.154. 
JRM, 2022, vol.10, no.3

160. Chen, S., Patil, S. A., Schröder, U. (2018). Substrate crossover effect and performance regeneration of the biofouled rotating air-cathode in microbial fuel cell. Frontiers in Energy Research, 6, 85. DOI 10.3389/ fenrg.2018.00085.

161. Oliot, M., Etcheverry, L., Bergel, A. (2016). Removable air-cathode to overcome cathode biofouling in microbial fuel cells. Bioresource Technology, 221, 691-696. DOI 10.1016/j.biortech.2016.09.095.

162. Kiely, P. D., Rader, G., Regan, J. M., Logan, B. E. (2011). Long-term cathode performance and the microbial communities that develop in microbial fuel cells fed different fermentation endproducts. Bioresource Technology, 102, 361-366. DOI 10.1016/j.biortech.2010.05.017.

163. Zhou, L., Liao, C., Li, T., An, J., Du, Q. et al. (2018). Regeneration of activated carbon air-cathodes by half-wave rectified alternating fields in microbial fuel cells. Applied Energy, 219, 199-206. DOI 10.1016/j. apenergy.2018.03.022.

164. Song, J., Liu, L., Yang, Q., Liu, J., Yu, T. et al. (2015). PVDF layer as a separator on the solution-side of aircathodes: The electricity generation, fouling and regeneration. RSC Advances, 5, 52361-52368. DOI 10.1039/ C5RA08717A.

165. Morris, J. M., Jin, S., Wang, J., Zhu, C., Urynowicz, M. A. (2007). Lead dioxide as an alternative catalyst to platinum in microbial fuel cells. Electrochemistry Communications, 9, 1730-1734. DOI 10.1016/j. elecom.2007.03.028.

166. Khilari, S., Pandit, S., Ghangrekar, M. M., Das, D., Pradhan, D. (2013). Graphene supported $\alpha-\mathrm{MnO}_{2}$ nanotubes as a cathode catalyst for improved power generation and wastewater treatment in single-chambered microbial fuel cells. RSC Advances, 3, 7902. DOI 10.1039/c3ra22569k.

167. Li, S., Cheng, C., Thomas, A. (2017). Carbon-based microbial-fuel-cell electrodes: From conductive supports to active catalysts. Advanced Materials, 29, 1602547. DOI 10.1002/adma.201602547.

168. Das, I., Das, S., Ghangrekar, M. M. (2020). Application of bimetallic low-cost CuZn as oxygen reduction cathode catalyst in lab-scale and field-scale microbial fuel cell. Chemical Physics Letters, 751, 137536. DOI 10.1016/j. cplett.2020.137536.

169. Noori, M. D. T., Mukherjee, C. K., Ghangrekar, M. M. (2017). Enhancing performance of microbial fuel cell by using graphene supported $\mathrm{V}_{2} \mathrm{O}_{5}$-nanorod catalytic cathode. Electrochimica Acta, 228, 513-521. DOI 10.1016/j. electacta.2017.01.016.

170. Li, Y., Li, Q., Wang, H., Zhang, L., Wilkinson, D. P. et al. (2019). Recent progresses in oxygen reduction reaction electrocatalysts for electrochemical energy applications. Electrochemial Energy Reviews, 2, 518-538. DOI 10.1007/s41918-019-00052-4.

171. Shi, X., Zhang, J., Huang, T. (2018). The key roles of trace iron for nitrogen, sulfur dual-doped carbon nanospheres as high efficient oxygen reduction catalyst. Journal of Materials Science, 53, 1404-1413. DOI 10.1007/s10853-017-1605-5.

172. Wang, L., Ambrosi, A., Pumera, M. (2013). "Metal-free" catalytic oxygen reduction reaction on heteroatomdoped graphene is caused by trace metal impurities. Angewandte Chemie, 125, 14063-14066. DOI 10.1002/ ange.201309171. 